Published in Opsearch, 2016, pp.1-23 which should be cited to refer to this work

\title{
Optimal ordering policy for newsvendor models with bidirectional changes in demand using expert judgment
}

\author{
Madhukar Nagare ${ }^{1}$, Pankaj Dutta ${ }^{1, *}$, Naoufel Cheikhrouhou ${ }^{2}$ \\ ${ }^{1}$ Shailesh J. Mehta School of Management, Indian Institute of Technology Bombay, Powai, Mumbai- \\ 400076, India \\ ${ }^{2}$ Haute école de gestion de Genève, HES-SO// University of Applied Sciences Western Switzerland, CH- \\ 1227, Geneva, Switzerland
}

\begin{abstract}
Demand forecast is a critical determinant of order quantity under newsvendor problem (NVP) framework and warrants major revision in the event of changing circumstances or happening of some unforeseen events having potential to alter the demand. Retailers of single period products such as fashion apparels are required to pass their orders far ahead of selling seasons and apply preseason two-stage ordering procedure, where an initial order (first stage) is followed by a final confirmed order (second stage). The enterprise forecasting experts may get additional information related to the occurrence of some unforeseen events that may significantly impact the initial demand estimation. In this paper, the potential impact of such events is combined using a weight factor to obtain revised demand forecasts. In this context, this paper develops inventory models under NVP framework to determine the optimal order quantity and weight factor on the basis of revised forecasts. Considering the bidirectional changes in demand, we formulate a unique objective function that operates as a profit maximization function for the positive demand adjustment and turns into a cost minimization function for the negative demand adjustment. Models developed without constraints at first instance are extended subsequently by incorporating constraints of budget limits, storage space capacity and required service level. Near closed form expressions of decision variables for four demand distributions with multiplicative demand forms are presented. The results demonstrate economic benefits of using revised demand through models developed, negative impact of constraints, and role of demand distribution entropy in determining the order size and expected profit.
\end{abstract}

Keywords: Inventory. Newsvendor problem. Expert judgment. Demand forecasting. Contextual information. Constraints.

\section{Introduction}

The retailing business environment of single period products (SPP) such as fashion apparels, holiday merchandize, sports goods, seasonal goods is characterized by a single and short selling season with high demand uncertainty, a long lead time with a purchasing commitment longer before the actual sales, a low salvage value and a limited possibility to increase supplies. In this context, the classical single-period problem also known as newsvendor problem is extensively used as a model to determine the procurement quantity of SPP for single ordering that maximizes the expected profit under probabilistic demand. Four review papers by Gallego and Moon [1], Khouja [2], Qin et al. [3], Kalpana and Kaur [4] provide rich information on the NVP. Demand distribution information is a critical input to the model. However, demand information is severely limited, uncertain and imprecise at the time of ordering because of the early placement of the order and novelty of the product involved. In such circumstances, demand forecast for the upcoming selling season is determined subjectively (Lau and Lau [5], Petrovic et al [6], Urban and Baker [7], Alfares and Elmorra [8], Dutta and Chakraborty [9], Yu et al. [10], Qin and Kar [11], Rossi et al. [12]).Expert judgement is recognised as an indispensable component of forecasting and much research attention

${ }^{*}$ Corresponding author

Email address: pdutta@iitb.ac.in (P. Dutta) 
has been directed at understanding and improving its use with feedback, decomposition, combination and correction (Lawrence et al.[13]).The expert judgment is used in conjunction with quantitative methods to improve the demand forecast particularly when the past sales data is limited as judgmental approach has ability to integrate the contextual information into the forecast (Webby and O'Connor [14]). The most common approach to forecasting demand is to generate initial forecast based on previous demand pattern using statistical methods and subsequently integrate with the judgmental adjustment provided by expert having domain knowledge and contextual information to arrive at 'final forecast'. The adjustment is effected to incorporate demand effects of potentially relevant contextual information about special events/exceptional circumstances that are not reflected in the initial forecast or of information that is difficult to include in a statistical model. The integration would be more beneficial under conditions of relevant quantitative data, judgmental inputs provide different information, unbiased judgments (Armstrong and Callopy[15]) and reliable information about the events (Goodwin and Fildes [16], Fildes et al [17]). Numerous studies have shown that integrating the forecasts improves accuracy (Lobo and Nair [18], Batchelor and Dua [19], Webby et al.[20]).

Retailers of SPP (e.g. fashion apparel) have to pass their orders several months before the selling season due to the long procurement lead time and to take advantage of lower prices (Mostard et al. [21]). In such cases, the pre-season two stage ordering is practiced; retailers pass their orders to their suppliers before the selling season at two distinct moments. A soft order is passed at initial stage when the booking starts, and at stage two, when additional demand information is gained; the order is confirmed with possibility of modification using different possible methods of demand information updating (Choi et al. [22]). The time interval between the placement of the soft order and the confirmation of the order may provide additional contextual information on change in business (demand) environment, of recent events and of impending (future) events having potential to alter the demand during the selling season significantly. The forecasting experts having domain knowledge and contextual information would estimate the potential impact of additional contextual information and impending events on demand (Choi [23], Sanders and Ritzman [24]).In this context, integrating expert judgment would prove valuable as experts often know of recent events whose effects have not yet been observed, of events that have occurred in the past but are not expected to recur in the future, or of events that have not occurred in the past but are expected in the future (Armstrong and Callopy [14]). Marmier and Cheikhrouhou [25] present a refinement in eliciting demand impact of contextual information using expert judgment in more objective manner and integrating it into a mathematical forecast and demonstrated the improvement of forecast accuracy. The present paper uses this method in determining the demand adjustment and more details are given in section 2.1. Recently, Yan and Wang [26] presented a newsvendor model with capital constraint and demand forecast update with two instants to order from the supplier prior to the selling season.

The size and sign of potential impact for each of exceptional events/ circumstances is determined separately by the experts and the aggregate of these potential impacts is termed as demand adjustment in this paper and is integrated to the initial forecast to obtain a (final) revised demand forecast. This decomposition approach add more objectivity (and reduces bias like over optimism) and as thrust of the paper is to determine the order size using revised forecast, equal treatment is effected to the sign of adjustment. Further, size of adjustment relative to initial forecast tend to large as events of significant demand are considered, demand adjustment would prove more effective in improving forecast accuracy than smaller ones [17] .

The existence of the bias towards making overly positive adjustments or as a consequence of asymmetric management incentives is evident in literature [17]. The bias has been reduced by developing model with different levels of complexity to integrate expert judgment with statistical forecast. For instance, Blattberg and Hoch [27] assign equal weight of importance to both the approaches. Fildes et al. [17] provide a model based on linear regression that distinguishes the weight of statistical and judgmental forecasting considering the adjustments sign. The differences involved between positive and negative adjustments prompted the use of non-linear models that employs state dependent parameter estimation methods (Trapero et al. [28]).The rigour involved in these methods 
has not been employed in this paper, however the paper determines weight assigned to demand adjustment for different purpose. It considers initial demand forecast without alteration as it is based on hard demand data. However, a weight is assigned to the demand adjustment, to signal its acceptability to a decision maker (DM). Although this family of methods shows improvement of the forecast accuracy, demand adjustment provided by the experts may not be acceptable in its entirety to a decision maker (DM). In fact, his experience, the credibility of the experts, or the risk involved might refrain from adopting the adjusted forecasts. In this case, in the present paper, a weight factor $\mathrm{W}(0 \leq \mathrm{W} \leq 1)$ is associated with the demand adjustment as a decision variable to mitigate the uncertainty of the event occurrence.

On the other side, scenarios where the demand adjustment is positive and negative both should be considered in modeling. For example, the increase of the advertisement expenditure, in normal course, leads to an increase of the demand. However, in some cases, the overall result of an advertisement campaign can be a demand decrease due to combative counter measures employed by the competitors. Though, Khouja and Robbins [21], Lee and Hsu [22], Dai and Meng [23] consider only a unidirectional demand change, where they consider a demand increase due to advertising expenditure. To the best of the authors' knowledge, both "positive and/or negative" impact of unexpected events through expert judgment under NVP setting has not been addressed. Furthermore, the consideration of bidirectional change in demand necessitates two different models of demand adjustments - profit maximization for positive adjustment and cost minimization for negative adjustment (explained in model development section 2.2) (Lau [24], Khouja [2], Kao and Hsu [25], Khouja and Robbins [21]). Therefore, the contribution of the paper is stated as: A unique objective function is formulated that considers the bidirectional demand adjustments and determines the optimal procurement quantity. The inventory models under the NVP framework proposed determine the optimal weight factor and order quantity using a revised demand that captures the potential impact of impending events in an intuitive and integrative manner. The central problem first addresses models without constraints for both demand adjustments. Subsequently, these models are extended by imposing constraints for practical considerations. The constraints do not allow the revised order quantity to exceed an upper limit in the case of positive demand adjustment due to limited fund/storage capacity and to fall under a lower limit in the case of negative demand adjustment in order to maintain a target service level (Jammernegg and Kischka [26], Shi et al. [27], Abdel-Malek and Otegbeye [28]). A one-dimensional search algorithm is proposed to find the optimal values of the Lagrangian multipliers required in the constrained optimization problems. Near closed-form expressions are obtained for four demand distributions, viz.; uniform, normal, triangular and exponential. The results of the models are illustrated with a real example taken from a retailer of women ethnic fashion apparel.

The rest of the paper is organized as follows. Section 2 being core of the paper include a summary on the basic NVP; method to obtain the revised demand forecast; development of the inventory models with bidirectional demand changes. Sub-section 2.3 and 2.4 extend these models by imposing constraints of service level and order size constraint respectively for practical consideration. Sub-section 2.5 provides a search algorithm to find the optimal value of the Lagrangian multipliers. Section 3 offers a closed-form expression of the expectation for the four demand distributions. Section 4 illustrates the models with numerical experiments on the basis of a real example and discusses the results. Finally, section 5 concludes the paper along with managerial implication and opens new research directions.

\section{Model development}

Consider the NVP with multiplicative form of stochastic demand. The following notations are used throughout the paper:

C unit purchase cost

$\mathrm{P} \quad$ unit selling price

$\mathrm{V}$ unit salvage value

$\mathrm{S}$ unit shortage penalty cost 


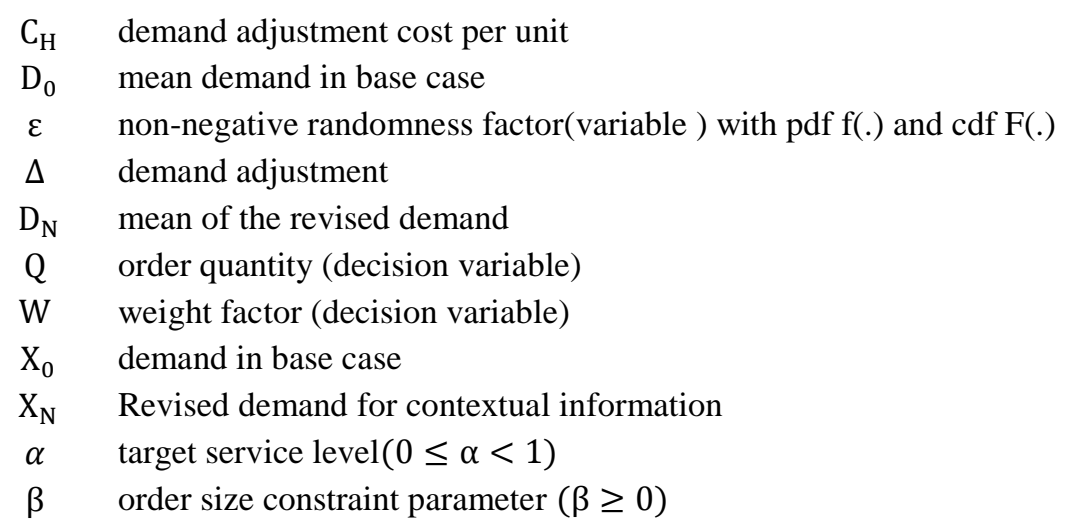

The initial demand forecast is the basis of the soft order of stage one. Although it is based on scarce past demand data of similar products, the initial forecast is assumed to be known with a statistical distribution form and its corresponding parameters. It is referred to as base demand in this paper and is assumed to be stochastic, with multiplicative form $\mathrm{X}_{0}=\mathrm{D}_{0}$. $\varepsilon$; where $\mathrm{D}_{0}$ is the mean demand and $\varepsilon$ is the randomness factor (with mean equal to 1 and a standard deviation equal to $\sigma_{0}$ ). Thus, the mean and the standard deviation (SD) of the base demand are $\mathrm{D}_{0}$ and $\mathrm{D}_{0} \sigma_{0}$ respectively. The probability density function (pdf) of the random variable $\varepsilon$ is defined as

$g(x)=\frac{1}{D_{0}} f\left(\frac{x}{D_{0}}\right) ; x \in[0, \infty)$

The case hereafter is referred to as base case. Given the expressions for the optimal procurement quantity and the expected profit for the base demand (Lau [32], Khouja and Robbins [29], Wang and Hu [37]), the profit function for an order size $Q$ is:

$\pi_{0}=P \min \left(Q, X_{0}\right)-C Q+V\left(Q-X_{0}\right)^{+}-S\left(X_{0}-Q\right)^{+}$

The terms in (1) are respectively: the sales revenue from the realized demand $X_{0}$; the purchase cost for an order size of Q; the salvage value realized from the left over inventory, if the realized demand is less than Q; the shortage penalty cost when demand exceeds the order quantity.

The expected profit function obtained from (1) is

$E\left(\pi_{0}\right)=(P-V) D_{0}-(C-V) Q-(P-V+S) \int_{Q}^{\infty}(x-Q) f(x) d x$

The optimal base order quantity $\left(\mathrm{Q}_{0}^{*}\right)($ soft order $)$ is

$\mathrm{Q}_{0}^{*}=\mathrm{D}_{0} \mathrm{~F}^{-1}\left[\frac{(\mathrm{P}-\mathrm{C}+\mathrm{S})}{(\mathrm{P}-\mathrm{V}+\mathrm{S})}\right]=\mathrm{D}_{0} \mathrm{~F}^{-1}(\mathrm{k})$

where $\mathrm{k}=(\mathrm{P}-\mathrm{C}+\mathrm{S}) /(\mathrm{P}-\mathrm{V}+\mathrm{S})$ is the critical ratio.

The optimal expected profit is

$E\left(\pi_{0}\right)^{*}=D_{0}\left[(P-V+S) \int_{0}^{F^{-1}(k)} x f(x) d x-S\right]$

\subsection{Revision of demand using contextual information}

The demand impact of additional contextual information gathered between two stages of ordering is estimated by the experts having domain knowledge and is integrated with the initial forecast to obtain the revised demand forecast. Domain knowledge is knowledge gained by practitioners through experience as part of their jobs and develop understanding of many cause-effect relationships and environmental cues. Specific information available in the forecast environment is called contextual information and includes information about events and changes such as substantial price variation, unanticipated arrival of a competing product in the market, consolidation among competitors, an impending strike, new policies that may affect forecasts, transportation delays due to inclement 
weather or even unplanned advertising campaign. Domain knowledge enables the practitioner to evaluate the importance of specific contextual information (Webby et al.[20]).

Marmier and Cheikhrouhou [25] provide a method to determine the aggregate impact in an objective manner using expert judgment. The underlying principle in estimating the size of impact is splitting the judgmental task into smaller and cognitively less demanding tasks, to improve accuracy and then aggregating the resulting judgments. Three event characteristics are considered for this purpose: irregular and infrequent occurrence, significant impact on demand and advanced identification along with their potential impact. Based on the kind of impact, the events and other causal variables of the forecasting environment (context) are categorized under four contextual factors and are listed in Table 1 along with the associated potential impact provided by the experts. Thus, an aggregate impact $(\Delta)$ of events using the four contextual factors, referred to hereafter as demand adjustment, is the algebraic sum of the impact of these factors i.e. $\Delta=\sum_{\mathrm{i}=1}^{4} \Delta_{\mathrm{i}}$. The demand adjustment can be positive or negative and accordingly, there would be either an increase or a decrease of the base demand.

Table 1 Event based contextual factors

\begin{tabular}{|l|l|l|c|}
\hline $\begin{array}{l}\text { Contextual } \\
\text { Factors }\end{array}$ & Meaning & $\begin{array}{l}\text { Illustrative } \\
\text { Example }\end{array}$ & $\begin{array}{l}\text { Potential } \\
\text { impact }\end{array}$ \\
\hline $\begin{array}{l}\text { Quantum jump } \\
\text { factor }\end{array}$ & $\begin{array}{l}\text { Impact of a non-repetitive event is } \\
\text { permanent. }\end{array}$ & $\begin{array}{l}\text { Addition of new } \\
\text { customers }\end{array}$ & $\Delta_{1}$ \\
\hline $\begin{array}{l}\text { Trend change } \\
\text { factor }\end{array}$ & Factor modifies the demand trend. & Increase in price & $\Delta_{2}$ \\
\hline $\begin{array}{l}\text { Transient } \\
\text { factor }\end{array}$ & $\begin{array}{l}\text { Impacts the demand only during a time } \\
\text { period in which it occurs. }\end{array}$ & Strike & $\Delta_{3}$ \\
\hline $\begin{array}{l}\text { Transferred } \\
\text { impact factor }\end{array}$ & $\begin{array}{l}\text { The impact is transferred from one set } \\
\text { of periods to another set without } \\
\text { changing the global forecasts of the } \\
\text { related consecutive periods. }\end{array}$ & $\begin{array}{l}\text { Discount sale offer } \\
\text { for limited period. }\end{array}$ & $\Delta_{4}$ \\
\hline
\end{tabular}

Considering that DMs may have different points of view with regard to the demand adjustment provided by the experts, there is the possibility to take into account only part of this adjustment. This is done by introducing a weight factor $\mathrm{W}(0 \leq \mathrm{W} \leq 1)$. For example, if the demand adjustment suggested by the experts is 500 units, but the DM prefers to order only 300 extra units that would mean he has taken a weight factor of $\mathrm{W}=0.6$. The weight factor so defined is a decision variable and is used to define the mean and the standard deviation of the revised stochastic demand $\mathrm{X}_{\mathrm{N}}=\mathrm{D}_{\mathrm{N}} \cdot \varepsilon$ with $\mathrm{D}_{\mathrm{N}}=\left(\mathrm{D}_{0}+\mathrm{W} \Delta\right)$ and $\sigma_{\mathrm{N}}=\mathrm{D}_{\mathrm{N}} \sigma_{0}$.

\subsection{NVP with demand adjustment using contextual information}

The revised demand $\left(\mathrm{X}_{\mathrm{N}}\right)$ obtained is used in the development of models under the NVP framework. Details of the model development are given below.

\subsubsection{Development of profit function}

The profit function (1) is redefined with two decision variables: the order quantity $(\mathrm{Q})$ and the weight factor $(\mathrm{W})$, and is given below:

$\pi=P \min \left(\mathrm{Q}, \mathrm{X}_{\mathrm{N}}\right)-\mathrm{CQ}+\mathrm{V}\left(\mathrm{Q}-\mathrm{X}_{\mathrm{N}}\right)^{+}-\mathrm{S}\left(\mathrm{X}_{\mathrm{N}}-\mathrm{Q}\right)^{+}-\mathrm{C}_{\mathrm{H}}|\Delta| \mathrm{W}^{\gamma}$

$X_{0}$ in (1) is not only replaced by the new demand $X_{N}$ in (4). It has been fundamentally altered because $X_{N}$ is an implicit function of the decision variable $\mathrm{W}$, with $\mathrm{X}_{\mathrm{N}}=\left(\mathrm{D}_{0}+\mathrm{W} \Delta\right) \varepsilon$. Moreover, the term $\mathrm{C}_{\mathrm{H}}|\Delta| \mathrm{W}^{\gamma}$ represents the cost adjustment due to the adjustment of demand. $\mathrm{C}_{\mathrm{H}}$ is the demand adjustment cost per unit [of demand adjusted $\Delta$ ] and can be interpreted as: (i) a penalty per demand unit charged to a buyer due to the modification of his soft order, (ii) advertising expenditure for accrued demand. Experts may provide information on the possibility of an advertising expenditure and on the corresponding increase in demand, and thus provide an advertising cost per unit of accrued demand, or (iii) an adjustment of the objective function for the loss in revenue per unit due to discounts. 
A discount brings additional demand that the experts may refer to. As the NVP provides only one selling price (P) for the entire selling season, the loss of revenue incurred per unit due to discounting can be construed as $\mathrm{C}_{\mathrm{H}}$.

As the weight factor (W) is a decision variable, its value varies from 1 if a full confidence is given to the expert assessment of the demand adjustment, to 0 if no confidence is given. The optimal value of weight factor is critically dependent on $\mathrm{C}_{\mathrm{H}}$ and has inverse relationship. Acting on the expert advice on the demand adjustment involves a risk and a consequent cost represented by the total demand adjustment cost. As the latter varies nonlinearly with the corresponding risk, the exponent $\gamma(\gamma>1)$ maintains the total demand adjustment cost as a nonlinear function.

\subsubsection{Generalisation of the model}

The model considers positive or negative demand adjustment. For $\Delta>0$, eq. (4) represents the profit function and its maximization would give the optimal value of the order quantity and the weight factor. However, eq. (4) cannot be used for $\Delta<0$, as the analytical process of profit maximization would always set the weight factor to zero to minimize the diminishing effect of the negative demand adjustment on the demand. In other words, using a profit maximization in a case where $\Delta<0$ would always result in ignoring the valuable suggestion of demand reduction provided by the experts by setting the weight factor to zero. The benefit of cost minimization in case of $\Delta<0$ inclusive of loss of business opportunity for the unmet demand viz.P $\left(\mathrm{X}_{\mathrm{N}}-\mathrm{Q}\right)^{+}$through optimization can be sizable and hence cannot be ignored. Therefore to take into consideration of the negative demand adjustment, objective should be cost minimization for $\Delta<0$ as it will not allow automatic setting of weight factor to zero by the optimization process.

In order to generalize the formulation of the problem, eq (1) is converted into a cost minimization problem. The optimal order quantity is $\mathrm{Q}_{0}^{*}=\mathrm{D}_{0} \mathrm{~F}^{-1}[(\mathrm{C}-\mathrm{S}) /(\mathrm{V}-\mathrm{S})]$, which is different from the one obtained for the profit maximization case i.e. $\mathrm{Q}_{0}^{*}=\mathrm{D}_{0} \mathrm{~F}^{-1}[(\mathrm{P}-\mathrm{C}+\mathrm{S}) /(\mathrm{P}-\mathrm{V}+\mathrm{S})]$. Thus, we develop a formulation of the objective function that would give only one soft order size under single decision making in the base case (if the DM does not rely on the experts opinion and set the weight $\mathrm{W}=0$ ) regardless of the followed approach - cost minimization or profit maximization.

\subsubsection{Development of NVP solutions with adjusted forecasts}

A single objective function applicable to both positive and negative demand adjustments is formulated. Eq. (4) is modified using the identity $\min \left(\mathrm{Q}, \mathrm{X}_{\mathrm{N}}\right)=\mathrm{X}_{\mathrm{N}}-\left(\mathrm{X}_{\mathrm{N}}-\mathrm{Q}\right)^{+}($Gallego and Moon [1]) and taking the objective function as

$E(\pi)=\mathrm{PD}_{\mathrm{N}}-\mathrm{CQ}+\mathrm{VE}\left(\mathrm{Q}-\mathrm{X}_{\mathrm{N}}\right)^{+}-(\mathrm{P}+\mathrm{S}) E\left(\mathrm{X}_{\mathrm{N}}-\mathrm{Q}\right)^{+}-\mathrm{C}_{\mathrm{H}}|\Delta| \mathrm{W}^{\gamma}$

A binary variable $(\theta)$ is introduced to allow the use of the single objective function for both demand adjustments. The optimization problem is given below:

$\operatorname{Max} . E(\mathrm{OF})=\theta \mathrm{PD}_{\mathrm{N}}-\mathrm{CQ}+\mathrm{VE}\left(\mathrm{Q}-\mathrm{X}_{\mathrm{N}}\right)^{+}-(\mathrm{P}+\mathrm{S}) E\left(\mathrm{X}_{\mathrm{N}}-\mathrm{Q}\right)^{+}-\mathrm{C}_{\mathrm{H}}|\Delta| \mathrm{W}^{\gamma}$

where $\theta=\left\{\begin{array}{ccc}1 & \text { if } & \Delta \geq 0 \\ 0 & \text { if } & \Delta<0\end{array}\right.$

When $\theta=1$, the objective function is a profit function. However, when $\theta=0$, maximizing the objective function with negative cost terms is equivalent to minimizing the total costs. The term $(P+S)\left(X_{N}-Q\right)^{+}$in (6) in the cost minimization case represents a loss of sales revenue (loss of business opportunity) for the unsatisfied demand in addition to the shortage penalty cost (Hillier and Liebermann [38], Kao and Hsu [33]).

Using the identity $\left(\mathrm{Q}-\mathrm{X}_{\mathrm{N}}\right)^{+}=\left(\mathrm{Q}-\mathrm{X}_{\mathrm{N}}\right)+\left(\mathrm{X}_{\mathrm{N}}-\mathrm{Q}\right)^{+}$, we derive the optimisation problem as

$\operatorname{Max} \cdot E(\mathrm{OF})=\theta \mathrm{PD}_{\mathrm{N}}-(\mathrm{C}-\mathrm{V}) \mathrm{Q}-\mathrm{VD}_{\mathrm{N}}-(\mathrm{P}-\mathrm{V}+\mathrm{S}) \int_{\mathrm{Q}}^{\infty}(\mathrm{x}-\mathrm{Q}) \mathrm{g}(\mathrm{x}) \mathrm{dx}-\mathrm{C}_{\mathrm{H}}|\Delta| \mathrm{W}^{\gamma}$ 
The randomness factor of the revised stochastic demand can be expressed as $\varepsilon=X_{N} / D_{N}$. The revised demand $X_{N}$ with continuously differentiable density function holds the following relations (Wang et al. [39]):

$g(x)=\frac{1}{D_{N}} f\left(\frac{x}{D_{N}}\right) ; x \in[0, \infty)$.

Thus, eq. (7) can be restated as

$\operatorname{Max} . E(\mathrm{OF})=\theta \mathrm{PD}_{\mathrm{N}}-(\mathrm{C}-\mathrm{V}) \mathrm{Q}-\mathrm{VD}_{\mathrm{N}}-(\mathrm{P}-\mathrm{V}+\mathrm{S}) \int_{\frac{\mathrm{Q}}{\mathrm{D}_{\mathrm{N}}}}^{\infty}\left(\mathrm{D}_{\mathrm{N}} \mathrm{x}-\mathrm{Q}\right) \mathrm{f}(\mathrm{x}) \mathrm{dx}-\mathrm{C}_{\mathrm{H}}|\Delta| \mathrm{W}^{\gamma}$

A weight factor more than 1 is meaningless. Therefore, it is necessary to determine the lower bound of $\mathrm{C}_{\mathrm{H}}$, (termed as threshold value, $\mathrm{C}_{\mathrm{HT}}$ ) that ensures an optimum value of $\mathrm{W}$, noted $\mathrm{W}^{*}$. In this regard, Lemmal given below defines the conditions as:

Lemma 1.(i)For given values of $P, C, S, V$ and $\gamma$, the lower bound of $C_{H}$ that would ensure optimum weight factor $W^{*} \leq 1$ is given by

$C_{H} \geq \frac{((\theta-1) P-S) \Delta+(P-V+S) \Delta \int_{0}^{F^{-1}(k)} x f(x) d x}{\gamma|\Delta|}$

(ii) For given values of $P, C, S, V$ and $\gamma$, any other value of $C_{H}$ that does not satisfy the condition (i) would set the optimal weight $W^{*}$ to 1 .

Proof. The W represents weight assigned by a DM to the demand adjustment provided by the experts and it's any value more than 1 is superfluous and meaningless; therefore, $\mathrm{W} \leq 1$. The optimal weight factor $\mathrm{W}^{*}$ can be derived using (P1) and is proved in the following Theorem 1. To restrain the value of $\mathrm{W}^{*}$ to 1 the net value of terms in bracket (see eq. (12)) needs to be less than 1 i.e.

$\frac{((\theta-1) \mathrm{P}-\mathrm{S}) \Delta+(\mathrm{P}-\mathrm{V}+\mathrm{S}) \Delta \int_{0}^{\mathrm{F}^{-1}(\mathrm{k})} \mathrm{xf}(\mathrm{x}) \mathrm{dx}}{\gamma \mathrm{C}_{\mathrm{H}}|\Delta|} \leq 1$

That provides for the lower limit of $\mathrm{C}_{\mathrm{H}}$

$\mathrm{C}_{\mathrm{H}} \geq \frac{((\theta-1) \mathrm{P}-\mathrm{S}) \Delta+(\mathrm{P}-\mathrm{V}+\mathrm{S}) \Delta \int_{0}^{\mathrm{F}^{-1}(\mathrm{k})} \mathrm{xf}(\mathrm{x}) \mathrm{dx}}{\gamma|\Delta|}$

For two demand cases, the optimum values of $\mathrm{W}^{*}$ can be computed as

$\mathrm{C}_{\mathrm{H}} \geq \frac{(\mathrm{P}-\mathrm{V}+\mathrm{S}) \int_{0}^{\mathrm{F}^{-1}(\mathrm{k})} \mathrm{xf}(\mathrm{x}) \mathrm{dx}-\mathrm{S}}{\gamma}$ for $\Delta>0$,

$\mathrm{C}_{\mathrm{H}} \geq \frac{(\mathrm{S}+\mathrm{P})-(\mathrm{P}-\mathrm{V}+\mathrm{S}) \int_{0}^{\mathrm{F}^{-1}(\mathrm{k})} \mathrm{xf}(\mathrm{x}) \mathrm{dx}}{\gamma}$ for $\Delta<0$

Any other value of $\mathrm{C}_{\mathrm{H}}$ less than the threshold specified above would make $\mathrm{W}^{*}$ more than 1 which is meaningless. Thus, for the given values of model parameters $\mathrm{P}, \mathrm{C}, \mathrm{S}, \mathrm{V}$ and $\gamma$, the lower bound of $\mathrm{C}_{\mathrm{H}}$ that would ensure optimum weight factor $\mathrm{W}^{*} \leq 1$ is given in (8). This completes the proof of Lemma 1.

In light of Lemma 1, we propose the Theorem 1.

Theorem 1. For given values of $P, C, S, V, C_{H}$ and $\gamma$, the optimal weight factor, optimal order quantity and optimal expected profit for unconstrained NVP with demand $X_{N}=D_{N} \cdot \varepsilon$ revised for contextual information are expressed as follows

(i) Optimal weight

$W^{*}=\left[\frac{((\theta-1) P-S) \Delta+(P-V+S) \Delta \int_{0}^{F^{-1}(k)} x f(x) d x}{\gamma C_{H}|\Delta|}\right]^{\frac{1}{\gamma-1}}$

(ii) Optimal order quantity (confirmed order) 
$Q^{*}=\left(D_{0}+W^{*} \Delta\right) F^{-1}(k)$

(iii) Optimal expected profit

$E(\pi)^{*}=\left(D_{0}+W^{*} \Delta\right)\left[(P-V+S) \int_{0}^{F^{-1}(k)} x f(x) d x-S\right]-C_{H}|\Delta| W^{* \gamma}$

Proof. It is to be noted that the revised demand $\mathrm{X}_{\mathrm{N}}$ is replaced with $\mathrm{D}_{\mathrm{N}}$ in $(\mathrm{P} 1)$ using the relationship $\mathrm{X}_{\mathrm{N}}=$ $D_{N} \cdot \varepsilon$ and $g(x)=\frac{1}{D_{N}} f\left(\frac{x}{D_{N}}\right)$. To find the optimal order quantity $Q^{*}$, first derivative of (P1) with respect to $Q$ is equated to zero, which yields

$(V-C)+(P-V+S) \int_{\frac{Q}{D_{N}}}^{\infty} f(x) d x=0$

Using the following standard result and mean value $\mu=1$, we get

$\int_{\frac{Q}{D_{N}}}^{\infty} f(x) d x=\mu-\int_{0}^{\frac{Q}{D_{N}}} f(x) d x=1-\int_{0}^{\frac{Q}{D_{N}}} f(x) d x$

Substituting the above result in (9) and rearranging the terms, we get the expression for optimal ordering quantity for revised demand as

$\mathrm{Q}^{*}=\mathrm{D}_{\mathrm{N}} \mathrm{F}^{-1}\left(\frac{\mathrm{P}-\mathrm{C}+\mathrm{S}}{\mathrm{P}-\mathrm{V}+\mathrm{S}}\right)=\left(\mathrm{D}_{0}+\mathrm{W}^{*} \Delta\right) \mathrm{F}^{-1}(\mathrm{k})$;

where critical ratio $\mathrm{k}=\left(\frac{\mathrm{P}-\mathrm{C}+\mathrm{S}}{\mathrm{P}-\mathrm{V}+\mathrm{S}}\right)$

To prove that (P1) is strictly concave in $\mathrm{Q}$, the second derivative of $(\mathrm{P} 1)$ with respect to $\mathrm{Q}$ is found strictly negative as follows

$\frac{\partial^{2} E(\mathrm{OF})}{\partial \mathrm{Q}^{2}}=-(\mathrm{P}-\mathrm{V}+\mathrm{S}) \frac{1}{\mathrm{D}_{\mathrm{N}}} \mathrm{f}\left(\frac{\mathrm{Q}}{\mathrm{D}_{\mathrm{N}}}\right)<0$

The expected value of the objective function is obtained by substituting $\mathrm{Q}^{*}$ into (P1) as

$E(O F)=(\theta P-V) D_{N}+\left[(V-C)+(P-V+S) \int_{\frac{Q^{*}}{D_{N}}}^{\infty} f(x) d x\right] Q_{1}^{*}-(P-V+S) \int_{\frac{Q^{*}}{D_{N}}}^{\infty} D_{N} x f(x) d x-C_{H}|\Delta| W^{\gamma}$

The optimal weight factor $\mathrm{W}^{*}$ is obtained by setting derivative of the objective function (11) with respect to $\mathrm{W}$ to zero:

$(\theta P-V) D^{\prime}{ }_{N}-(P-V+S) D^{\prime}{ }_{N} \int_{\frac{Q^{*}}{D_{N}}}^{\infty} x f(x) d x-\gamma C_{H}|\Delta| W^{\gamma-1}=0$

i.e. $(\theta P-V) D^{\prime}{ }_{N}-(P-V+S) D^{\prime}{ }_{N}\left[1-\int_{0}^{\frac{Q^{*}}{D_{N}}} x f(x) d x\right]-\gamma C_{H}|\Delta| W^{\gamma-1}=0$

As $\mathrm{D}_{\mathrm{N}}$ is function of $\mathrm{W}$ and $\mathrm{D}^{\prime}{ }_{\mathrm{N}}=\Delta$, substituting and arranging the above equation result in

$\mathrm{W}^{*}=\left[\frac{((\theta-1) \mathrm{P}-\mathrm{S}) \Delta+(\mathrm{P}-\mathrm{V}+\mathrm{S}) \Delta \int_{0}^{\mathrm{F}^{-1}(\mathrm{k})} \mathrm{xf}(\mathrm{x}) \mathrm{dx}}{\gamma \mathrm{C}_{\mathrm{H}}|\Delta|}\right]^{\frac{1}{\gamma-1}}$

As $\gamma>1, \frac{\partial^{2} \mathrm{E}(\mathrm{OF})}{\partial \mathrm{W}^{2}}=-\gamma(\gamma-1)|\Delta| \mathrm{C}_{\mathrm{H}} \mathrm{W}^{\gamma-2}<0$, the optimum values of $\mathrm{W}^{*}$ for two demand adjustment cases is given below

$\mathrm{W}^{*}= \begin{cases}{\left[\frac{(\mathrm{P}-\mathrm{V}+\mathrm{S}) \int_{0}^{\mathrm{F}^{-1}(\mathrm{k})} \mathrm{xf}(\mathrm{x}) \mathrm{dx}-\mathrm{S}}{\gamma \mathrm{C}_{\mathrm{H}}}\right]^{\frac{1}{\gamma-1}}} & \text { for } \Delta>0, \\ {\left[\frac{(\mathrm{S}+\mathrm{P})-(\mathrm{P}-\mathrm{V}+\mathrm{S}) \int_{0}^{\mathrm{F}^{-1}(\mathrm{k})} \mathrm{xf}(\mathrm{x}) \mathrm{dx}}{\gamma \mathrm{C}_{\mathrm{H}}}\right]^{\frac{1}{\gamma-1}}} & \text { for } \Delta<0\end{cases}$

The optimum value of $\mathrm{W}$ obtained in (12) is used back in (10) to obtain $\mathrm{Q}^{*}$. Subsequently, the optimal expected value of the $\mathrm{OF}(\mathrm{P} 1)$ is 
$E(\mathrm{OF})^{*}=\left(\mathrm{D}_{0}+\mathrm{W}^{*} \Delta\right)\left[(\mathrm{P}-\mathrm{V}+\mathrm{S}) \int_{0}^{\mathrm{F}^{-1}(\mathrm{k})} \mathrm{xf}(\mathrm{x}) \mathrm{dx}+(\theta-1) \mathrm{P}-\mathrm{S}\right]-\mathrm{C}_{\mathrm{H}}|\Delta| \mathrm{W}^{* \gamma}$

The objective function (13) represents optimal expected profit for $\Delta>0$ and negative optimal expected cost for $\Delta<$ 0 . Therefore, by substituting the values of $\theta$ in (13) and adding expected sales revenue (viz. $P D_{N}$ ) to the resulting negative cost only in case of $\Delta<0$, we get the optimum expected profit for the unconstrained optimization problem as

$\mathrm{E}(\pi)^{*}=\left(\mathrm{D}_{0}+\mathrm{W}^{*} \Delta\right)\left[(\mathrm{P}-\mathrm{V}+\mathrm{S}) \int_{0}^{\mathrm{F}^{-1}(\mathrm{k})} \mathrm{xf}(\mathrm{x}) \mathrm{dx}-\mathrm{S}\right]-\mathrm{C}_{\mathrm{H}}|\Delta| \mathrm{W}^{* \gamma}$

Hence, the result of (10), (12) and (14) completes the proof of Theorem 1.

The demand adjustment for contextual information can be sizeable and that may lead to significant deviation of the revised optimal order quantity from the optimal base order size $\left(Q_{0}^{*}\right)$. Therefore, it is prudent to constraint revised order quantity within some limits for practical considerations. In case of $\Delta>0$, the revised order quantity is limited by an order size constraint for practical limitation of budget and storage space. For $\Delta<0$, the reduced revised order quantity may prove inadequate in meeting the service level targeted by a retailer. Therefore, a lower limit is placed on $\mathrm{Q}$ through a service level constraint. These two situations are discussed separately as follows:

\subsection{Imposition of service level constraint}

A lower limit is imposed on the revised order quantity using the service level constraint. The constraint is imposed in a way that the probability of attaining the targeted service level $(\alpha)$ is greater than $\eta(0 \leq \eta<1)$. The concept is equivalent to the chance constraint (Charnes and Cooper [40], Panda et al. [41], Nagar et al. [42]) and noted as $\mathrm{Ch}\left(\frac{\mathrm{Q}}{\mathrm{x}_{\mathrm{N}}} \geq \alpha\right) \geq \eta$; where $\eta$ is the chance factor. The constraint is expressed as

$\mathrm{Q} \geq \alpha\left(\mu+\sigma \mathrm{z}_{\eta}\right)=\alpha \mu+\alpha \sigma \mathrm{z}_{\eta}$

where $z_{\eta}=\Phi^{-1}(\eta), \Phi$ is the standard normal cdf and $\mu$ and $\sigma$ are the mean and standard deviation of the revised demand $X_{N}$. Substituting the values of the mean and the standard deviation of the revised demand $D_{N}$ and $\sigma_{0} D_{N}$ respectively in (15), we get

$\mathrm{Q}-\mathrm{A}\left(\mathrm{D}_{0}+\Delta \mathrm{W}\right) \geq 0 \quad$ where $\mathrm{A}=\alpha\left(1+\sigma_{0} \mathrm{z}_{\eta}\right)$

With $\theta=0$ in (P1), the constrained optimization problem for $\Delta<0$ is stated as follows:

Max. $E(\mathrm{OF})=-\left[(\mathrm{C}-\mathrm{V}) \mathrm{Q}+\mathrm{VD}_{\mathrm{N}}+(\mathrm{P}-\mathrm{V}+\mathrm{S}) \int_{\frac{\mathrm{Q}}{\mathrm{D}_{\mathrm{N}}}}^{\infty}\left(\mathrm{D}_{\mathrm{N}} \mathrm{x}-\mathrm{Q}\right) \mathrm{f}(\mathrm{x}) \mathrm{dx}+\mathrm{C}_{\mathrm{H}}|\Delta| \mathrm{W}^{\gamma}\right]$

subject to $\quad Q-A\left(D_{0}+\Delta w\right) \geq 0$

\subsection{Imposition of order size constraint}

The order size constraint is defined in terms of $Q_{0}^{*}$ as only accommodation for a limited amount of extra units is only possible. Therefore an order size constraint parameter $\beta,(\beta \geq 0)$ is introduced to limit the maximum revised order quantity (Abdel-Malek and Montanari [43]). The constraint is stated as

$\mathrm{Q} \leq(1+\beta) \mathrm{Q}_{0}^{*}$

When $\beta=0.1$, only $10 \%$ of additional inventory can be accommodated. Therefore, the constrained optimization problem for $\Delta>0$ is stated as follows:

$\operatorname{Max} . E(\mathrm{OF})=(\mathrm{P}-\mathrm{V}) \mathrm{D}_{\mathrm{N}}-(\mathrm{C}-\mathrm{V}) \mathrm{Q}-(\mathrm{P}-\mathrm{V}+\mathrm{S}) \int_{\frac{\mathrm{Q}}{\mathrm{D}_{\mathrm{N}}}}^{\infty}\left(\mathrm{D}_{\mathrm{N}} \mathrm{x}-\mathrm{Q}\right) \mathrm{f}(\mathrm{x}) \mathrm{dx}-\mathrm{C}_{\mathrm{H}}|\Delta| \mathrm{W}^{\gamma}$

Subject to $(1+\beta) Q_{0}^{*}-Q \geq 0$

The two constrained optimization problems (P2) and (P3) are solved using the Lagrangian multiplier method with the multipliers $\lambda_{\mathrm{i}}, \mathrm{i}=1,2$ respectively. 
The following Lemma 2 is introduced to define the lower limit of $\mathrm{C}_{\mathrm{H}}$ that ensures constrained weight factor $\mathrm{W}_{\mathrm{c}}^{*} \leq 1$.

Lemma 2.(i)For given values of $P, C, S, V, \gamma$ and $\lambda_{i}$, the lower bound of $C_{H}$ that would provide constrained optimal weight factor $\left(W_{c}^{*}\right)$ between 0 and 1 i.e. $0 \leq W_{c}^{*} \leq 1$ is

$C_{H} \geq \frac{(P+S)+\lambda_{1} A-(P-V+S) \int_{0}^{F^{-1}\left(k_{C}\right)} x f(x) d x}{\gamma}$ with $k_{C}=\frac{P-C+S+\lambda_{1}}{P-V+S}$ for $\Delta<0$
$C_{H} \geq \frac{(P-V+S) \int_{0}^{F^{-1}\left(k_{C}\right)} x f(x) d x-S}{\gamma}$ with $k_{C}=\frac{P-C+S-\lambda_{2}}{P-V+S}$ for $\Delta>0 ;$

(ii) For given values of $P, C, S, V, \gamma$ and $\lambda_{i}$, any other value of $C_{H}$ that does not satisfy the condition $(i)$ would set the optimum value $W_{c}^{*}$ to 1 .

The logic applicable to Lemma 2 is very similar to Lemma 1 and therefore proof is not presented to avoid unnecessary repetition. The Theorem 2 is proposed in light of Lemma 2.

Theorem 2. For given values of $P, C, S, V, C_{H}$ and $\gamma$, the optimal weight factor, order quantity and expected profit for constrained NVP with demand $X_{N}=D_{N} \cdot \varepsilon$ revised for contextual information are expressed as

(i) The optimal weight

$$
W_{c}^{*}= \begin{cases}{\left[\frac{(P+S)+\lambda_{1} A-(P-V+S) \int_{0}^{F^{-1}\left(k_{C}\right)} x f(x) d x}{\gamma C_{H}}\right]^{\frac{1}{\gamma-1}}} & \text { for } \Delta<0 \\ {\left[\frac{(P-V+S) \int_{0}^{F^{-1}\left(k_{C}\right)} x f(x) d x-S}{\gamma C_{H}}\right]^{\frac{1}{\gamma-1}}} & \text { for } \Delta>0\end{cases}
$$

(ii) The optimal order quantity(confirmed order)

$$
\mathrm{Q}_{\mathrm{c}}^{*}=\left(D_{0}+\Delta W_{c}^{*}\right) F^{-1}\left(k_{c}\right)
$$

(iii) The optimal expected profit

$$
E\left(\pi_{\mathrm{c}}\right)^{*}=\left(\mathrm{D}_{0}+W_{c}^{*} \Delta\right)\left[F^{-1}\left(k_{c}\right) \lambda+(P-V+S) \int_{0}^{F^{-1}\left(k_{c}\right)} x f(x) d x-S\right]-C_{H}|\Delta| W_{c}^{* \gamma}
$$

where $\lambda$ is the Lagrangian multiplier for two demand adjustment cases and takes the value $\lambda=-\lambda_{1}$ for $\Delta<$ 0 and $\lambda_{2}$ for $\Delta>0$.

Proof. Theorem 2 consists of two separate parts - proof of problem (P2) and (P3). The proof for problem (P2) is given here and proof for problem (P3) can be deduced using similar approach and therefore not provided.

The objectives function of (P2) is concave (as proved in Theorem 1) and the service level constraint is a linear inequality, so any feasible solution to the problem (P2) that satisfies the Kuhn-Tucker conditions is an optimal solution. A Lagrangian Multiplier method (with multiplier $\lambda_{1}$ ) is proposed. Therefore, the associated Lagrangian function is

$\mathrm{L}=\mathrm{E}(\mathrm{OF})-\lambda_{1}\left[\mathrm{~A}\left(\mathrm{D}_{0}+\Delta \mathrm{W}\right)-\mathrm{Q}\right]$

$=(V-C) Q-V D_{N}-(P-V+S) \int_{\frac{Q}{D_{N}}}^{\infty}\left(D_{N} x-Q\right) f(x) d x-C_{H}|\Delta| W^{\gamma}-\lambda_{1}\left[A\left(D_{0}+\Delta W\right)-Q\right]$

Equating the first derivatives of $\mathrm{L}$ with respect to $\mathrm{Q}$ to zero gives

$(V-C)+(P-V+S) \int_{\frac{Q}{D_{N}}}^{\infty} f(x) d x+\lambda_{1}=0$

which yields to

$\mathrm{Q}_{\mathrm{c}}^{*}=\mathrm{D}_{\mathrm{N}} \mathrm{F}^{-1}\left(\frac{\mathrm{P}-\mathrm{C}+\mathrm{S}+\lambda_{1}}{\mathrm{P}-\mathrm{V}+\mathrm{S}}\right)=\left(\mathrm{D}_{0}+\Delta \mathrm{W}_{\mathrm{c}}^{*}\right) \mathrm{F}^{-1}\left(\mathrm{k}_{\mathrm{c}}\right)$ 
wherek $_{\mathrm{c}}=\left(\frac{\mathrm{P}-\mathrm{C}+\mathrm{S}+\lambda_{1}}{\mathrm{P}-\mathrm{V}+\mathrm{S}}\right)$ is the critical ratio. The value of $\mathrm{Q}_{\mathrm{c}}^{*}$ obtained in (17) is substituted in the objective function $\mathrm{E}(\mathrm{OF})$ as defined in $(\mathrm{P} 2)$ and is derived as

$$
\begin{aligned}
E(\mathrm{OF}) & =\left[(\mathrm{V}-\mathrm{C})+(\mathrm{P}-\mathrm{V}+\mathrm{S}) \int_{\frac{\mathrm{Q}_{\mathrm{C}}^{*}}{\mathrm{D}_{\mathrm{N}}}}^{\infty} \mathrm{f}(\mathrm{x}) \mathrm{dx}\right] \mathrm{Q}_{\mathrm{c}}^{*}-(\mathrm{P}-\mathrm{V}+\mathrm{S}) \int_{\frac{\mathrm{Q}_{\mathrm{C}}^{*}}{\mathrm{D}_{\mathrm{N}}}}^{\infty} \mathrm{D}_{\mathrm{N}} \mathrm{x} f(\mathrm{x}) \mathrm{dx}-\mathrm{VD}_{\mathrm{N}}-\mathrm{C}_{\mathrm{H}}|\Delta| \mathrm{W}^{\gamma} \\
& =\left[(\mathrm{P}-\mathrm{C}+\mathrm{S})-(\mathrm{P}-\mathrm{V}+\mathrm{S}) \int_{0}^{\mathrm{F}^{-1}\left(\mathrm{k}_{\mathrm{c}}\right)} \mathrm{f}(\mathrm{x}) \mathrm{dx}\right] \mathrm{Q}_{\mathrm{c}}^{*}-\left[(\mathrm{P}+\mathrm{S})-(\mathrm{P}-\mathrm{V}+\mathrm{S}) \int_{0}^{\mathrm{F}^{-1}\left(\mathrm{k}_{\mathrm{c}}\right)} \mathrm{xf}(\mathrm{x}) \mathrm{dx}\right] \mathrm{D}_{\mathrm{N}}-\mathrm{C}_{\mathrm{H}}|\Delta| \mathrm{W}^{\gamma}
\end{aligned}
$$

Substituting $\int_{0}^{\mathrm{F}^{-1}\left(\mathrm{k}_{\mathrm{c}}\right)} \mathrm{f}(\mathrm{x}) \mathrm{dx}=\left(\frac{\mathrm{P}-\mathrm{C}+\mathrm{S}+\lambda_{1}}{\mathrm{P}-\mathrm{V}+\mathrm{S}}\right)$ and $\mathrm{Q}_{\mathrm{c}}^{*}=\mathrm{D}_{\mathrm{N}} \mathrm{F}^{-1}\left(\mathrm{k}_{\mathrm{c}}\right)$, we get,

$\mathrm{E}(\mathrm{OF})=\left[-\mathrm{F}^{-1}\left(\mathrm{k}_{\mathrm{c}}\right) \lambda_{1}+(\mathrm{P}-\mathrm{V}+\mathrm{S}) \int_{0}^{\mathrm{F}^{-1}\left(\mathrm{k}_{\mathrm{c}}\right)} \mathrm{xf}(\mathrm{x}) \mathrm{dx}-(\mathrm{P}+\mathrm{S})\right] \mathrm{D}_{\mathrm{N}}-\mathrm{C}_{\mathrm{H}}|\Delta| \mathrm{W}^{\gamma}$

Using (18), the Lagrangian function (16) can be rewritten as:

$\mathrm{L}=\left[-\mathrm{F}^{-1}\left(\mathrm{k}_{\mathrm{c}}\right) \lambda_{1}-(\mathrm{P}-\mathrm{V}+\mathrm{S}) \int_{0}^{\mathrm{F}^{-1}\left(\mathrm{k}_{\mathrm{c}}\right)} \mathrm{xf}(\mathrm{x}) \mathrm{dx}-(\mathrm{P}+\mathrm{S})\right] \mathrm{D}_{\mathrm{N}}-\mathrm{C}_{\mathrm{H}}|\Delta| \mathrm{W}^{\gamma}-\lambda_{1}\left[\mathrm{~A}\left(\mathrm{D}_{0}+\Delta \mathrm{W}\right)-\mathrm{Q}_{\mathrm{c}}^{*}\right]$

Setting the first derivative of $\mathrm{L}$ with respect to $\mathrm{W}$ to zero yields

$\left[-\mathrm{F}^{-1}\left(\mathrm{k}_{\mathrm{c}}\right) \lambda_{1}+(\mathrm{P}-\mathrm{V}+\mathrm{S}) \int_{0}^{\mathrm{F}^{-1}\left(\mathrm{k}_{\mathrm{c}}\right)} \mathrm{xf}(\mathrm{x}) \mathrm{dx}-(\mathrm{P}+\mathrm{S})\right] \mathrm{D}_{\mathrm{N}}{ }^{\prime}-\gamma \mathrm{C}_{\mathrm{H}}|\Delta| \mathrm{W}^{\gamma-1}-\lambda_{1}\left[\mathrm{~A} \Delta-\mathrm{D}_{\mathrm{N}}{ }^{\prime} \mathrm{F}^{-1}\left(\mathrm{k}_{\mathrm{c}}\right)\right]=0$

Substituting $\mathrm{D}_{\mathrm{N}}{ }^{\prime}=\Delta$ and rearranging the terms of above expression provides for optimum weight factor as

$\mathrm{W}_{\mathrm{c}}^{*}=\left[\frac{(\mathrm{P}-\mathrm{V}+\mathrm{S}) \Delta \int_{0}^{\mathrm{F}^{-1}\left(\mathrm{k}_{\mathrm{c}}\right)} \mathrm{xf}(\mathrm{x}) \mathrm{dx}-(\mathrm{P}+\mathrm{S}) \Delta-\lambda_{1} \mathrm{~A} \Delta}{\gamma \mathrm{C}_{\mathrm{H}}|\Delta|}\right]^{\frac{1}{\gamma-1}}$

Considering the negative sign of $\Delta$, the above expression result in

$\mathrm{W}_{\mathrm{c}}^{*}=\left[\frac{(\mathrm{P}+\mathrm{S})+\lambda_{1} \mathrm{~A}-(\mathrm{P}-\mathrm{V}+\mathrm{S}) \int_{0}^{\mathrm{F}^{-1}\left(\mathrm{k}_{\mathrm{c}}\right)} \mathrm{xf}(\mathrm{x}) \mathrm{dx}}{\gamma \mathrm{C}_{\mathrm{H}}}\right]^{\frac{1}{\gamma-1}}$

The $\mathrm{W}_{\mathrm{c}}^{*}$ obtained in (19) thus can be used back in (17) to obtain $\mathrm{Q}_{\mathrm{c}}^{*}$.

Thus the expression of (19) and (17) provides the respective optimum weight and order quantity for the problem (P2). Using (18), the subsequent optimum value of the objective function of (P2) is derived as

$E(\mathrm{OF})^{*}=\left(\mathrm{D}_{0}+\mathrm{W}_{\mathrm{c}}^{*} \Delta\right)\left[-\mathrm{F}^{-1}\left(\mathrm{k}_{\mathrm{c}}\right) \lambda_{1}+(\mathrm{P}-\mathrm{V}+\mathrm{S}) \int_{0}^{\mathrm{F}^{-1}\left(\mathrm{k}_{\mathrm{c}}\right)} \mathrm{xf}(\mathrm{x}) \mathrm{dx}-(\mathrm{P}+\mathrm{S})\right]-\mathrm{C}_{\mathrm{H}}|\Delta| \mathrm{W}_{\mathrm{c}}^{* \gamma}$

Optimal weight factor and the corresponding value of objective function for the problem (P3) can obtained following the similar procedure and given as follows

$\mathrm{W}_{\mathrm{c}}^{*}=\left[\frac{(\mathrm{P}-\mathrm{V}+\mathrm{S}) \int_{0}^{\mathrm{F}^{-1}\left(\mathrm{k}_{\mathrm{c}}\right)} \mathrm{xf}(\mathrm{x}) \mathrm{dx}-\mathrm{S}}{\gamma \mathrm{C}_{\mathrm{H}}}\right]^{\frac{1}{\gamma-1}}$

$E(\mathrm{OF})^{*}=\left(\mathrm{D}_{0}+\mathrm{W}_{\mathrm{c}}^{*} \Delta\right)\left[\mathrm{F}^{-1}\left(\mathrm{k}_{\mathrm{c}}\right) \lambda_{2}+(\mathrm{P}-\mathrm{V}+\mathrm{S}) \int_{0}^{\mathrm{F}^{-1}\left(\mathrm{k}_{\mathrm{c}}\right)} \mathrm{xf}(\mathrm{x}) \mathrm{dx}-\mathrm{S}\right]-\mathrm{C}_{\mathrm{H}}|\Delta| \mathrm{W}_{\mathrm{c}}^{* \gamma} ;$

where $\mathrm{k}_{\mathrm{c}}=\left(\frac{\mathrm{P}-\mathrm{C}+\mathrm{S}-\lambda_{2}}{\mathrm{P}-\mathrm{V}+\mathrm{S}}\right)$ is the critical ratio for $(\mathrm{P} 3)$.

Using (22) and addition of expected sales revenue to optimal expected negative cost of (20) for $\Delta<0$, we arrive at the optimum expected profit for the constrained optimization problem as

$\mathrm{E}\left(\pi_{\mathrm{c}}\right)^{*}=\left(\mathrm{D}_{0}+\mathrm{W}_{\mathrm{c}}^{*} \Delta\right)\left[\mathrm{F}^{-1}\left(\mathrm{k}_{\mathrm{c}}\right) \lambda+(\mathrm{P}-\mathrm{V}+\mathrm{S}) \int_{0}^{\mathrm{F}^{-1}\left(\mathrm{k}_{\mathrm{c}}\right)} \mathrm{xf}(\mathrm{x}) \mathrm{dx}-\mathrm{S}\right]-\mathrm{C}_{\mathrm{H}}|\Delta| \mathrm{W}_{\mathrm{c}}^{* \gamma}$

where $\lambda$ represents Lagrangian multiplier for two demand adjustment cases and takes the value $\lambda=-\lambda_{1}$ for $\Delta<$ 0 and $\lambda_{2}$ for $\Delta>0$. 
Hence, the result of (17), (19), (21) and (23) completes the proof of Theorem 2.

The next step is to find the optimal Lagrangian multiplier for (P1) and (P2). An algorithm to find the Lagrangian multiplier is provided in the next section.

\subsection{Proposed resolution algorithm}

Finding the optimal value of the Lagrangian multiplier $\left(\lambda_{i}\right.$ with $i=1,2$ for problem (P2) and (P3) respectively) for the given constrained optimization problems allows to determine the constrained critical ratio $\left(\mathrm{k}_{\mathrm{c}}\right), \mathrm{W}_{\mathrm{c}}^{*}$ and consequently $\mathrm{Q}_{\mathrm{c}}^{*}$ and $\mathrm{E}\left(\pi_{\mathrm{c}}\right)^{*}$.

First, we define a function $\mathrm{h}\left(\lambda_{\mathrm{i}}\right)$ with $(\mathrm{i}=1,2)$ such that

$h\left(\lambda_{i}\right)= \begin{cases}Q-A\left(D_{0}+\Delta W\right) & \text { for } \Delta<0 \text { and } i=1 \\ (1+\beta) Q_{0}^{*}-Q & \text { for } \Delta>0 \text { and } i=2\end{cases}$

The function $h\left(\lambda_{i}\right)$ is defined in such a way that $h\left(\lambda_{i}\right) \geq 0$ would satisfy the constraint for both defined cases of demand adjustments.

Lemma 3.There exist a unique $\lambda_{i}$ with $i=1,2$ such that $h\left(\lambda_{i}\right)=0$.

Proof. It is clear that $h\left(\lambda_{\mathrm{i}}\right)$ is continuous and strictly increasing in $\lambda_{i}$. The problems (P2) or (P3) turn into an unconstrained optimization problem at $\lambda_{\mathrm{i}}=0$. Thus at $\lambda_{\mathrm{i}}=0, \mathrm{~h}\left(\lambda_{\mathrm{i}}\right)<0$ as it violates the service level or the capacity constraint. In particular, the value of $\lambda_{\mathrm{i}}$ must be positive. Therefore, there exist two distinct values $\lambda_{\mathrm{i}}^{1}, \lambda_{\mathrm{i}}^{2}>$ 0 such that $\mathrm{h}\left(\lambda_{\mathrm{i}}^{1}\right) \mathrm{h}\left(\lambda_{\mathrm{i}}^{2}\right)<0$. This implies that there exist a unique $\lambda_{\mathrm{i}}$ such that $\mathrm{h}\left(\lambda_{\mathrm{i}}\right)=0$.

Therefore, the proposed one dimensional search algorithm would determine the optimal value of $\lambda_{\mathrm{i}}^{*}$ that satisfies $\mathrm{h}\left(\lambda_{\mathrm{i}}^{*}\right)=0$. The proposed algorithm has the following sequential steps:

Step1. Set $\lambda_{i}^{0}=0$ and obtain the values of $k_{c}$, and the decision variables $W_{c}^{*}$ and $Q_{c}^{*}$. If these values satisfy $h\left(\lambda_{i}^{0}\right) \geq$ 0 , the current solution is optimal. Otherwise, the current solution is infeasible and step 2 must be followed.

Step2. As $h\left(\lambda_{\mathrm{i}}^{0}\right)<0$, set next value of $\lambda_{\mathrm{i}}$ i.e. $\lambda_{\mathrm{i}}^{1}$ sufficiently large so that $\mathrm{h}\left(\lambda_{\mathrm{i}}^{1}\right)>0$.

Find $\lambda_{i}^{2}$, which is the arithmetic mean of $\lambda_{i}^{0}$ and $\lambda_{i}^{1}$ viz. $\lambda_{i}^{2}=\frac{\lambda_{i}^{0}+\lambda_{i}^{1}}{2}$. If $h\left(\lambda_{i}^{2}\right) \approx 0$, stop the iterations. Otherwise, proceed as follows:

Select either $\lambda_{1}^{0}$ or $\lambda_{1}^{1}$ such that $\mathrm{h}\left(\lambda_{\mathrm{i}}^{0}\right)$ or $\mathrm{h}\left(\lambda_{\mathrm{i}}^{1}\right)$ has the opposite sign to $\mathrm{h}\left(\lambda_{\mathrm{i}}^{2}\right)$ and find the mean with $\lambda_{\mathrm{i}}^{2}$ to obtain $\lambda_{\mathrm{i}}^{3}$ [viz. $\lambda_{i}^{3}=\frac{\lambda_{i}^{0}+\lambda_{i}^{2}}{2}$ or $\lambda_{i}^{3}=\frac{\lambda_{i}^{1}+\lambda_{i}^{2}}{2}$ ]. Continue the process until obtaining $h\left(\lambda_{i}^{m}\right)=0$ for $m \geq 3$. This value is the optimal one for $\lambda_{\mathrm{i}}$ and is renamed as $\lambda_{\mathrm{i}}^{*}$.

Step3. Using $\lambda_{\mathrm{i}}^{*}$, find the value of $\mathrm{k}_{\mathrm{c}}$ and $\mathrm{W}_{\mathrm{c}}^{*}$. $\mathrm{W}_{\mathrm{c}}^{*}$ is set to 1 whenever its computed value is higher than 1 .

Subsequently, calculate the values of $\mathrm{Q}_{\mathrm{c}}^{*}$ and $\mathrm{E}\left(\pi_{\mathrm{c}}\right)^{*}$ using Theorem 2 .

\section{Applications to specific distributions}

For simplification reasons, we denote $\mathrm{H}($.$) for the expression of the expectation and \mathrm{T}=\mathrm{F}^{-1}(\mathrm{k})$.

\section{Normal distribution}

The normal distribution $\mathrm{N} \sim\left(\mu, \sigma^{2}\right)$ for a variable $\mathrm{x}$ with standard normal variate $z=\frac{x-\mu}{\sigma}=\frac{T-\mu}{\sigma}$ has the expectation $\mathrm{H}(\mathrm{z})=\int_{-\infty}^{\mathrm{z}} \mathrm{xf}(\mathrm{x}) \mathrm{dx}=\mu \Phi(\mathrm{z})-\sigma \varphi(\mathrm{z})$; where $\Phi(\mathrm{z})$ and $\varphi(\mathrm{z})$ are the standard normal cdf and pdf respectively.

\section{Uniform distribution}


The uniform distribution is defined over the support interval $[a, b]$. Thus, $T=a+(b-a) k$ and the expectation is $H(T)=\int_{a}^{T} x f(x) d x=\int_{a}^{T} \frac{x}{(b-a)} d x=\frac{T^{2}-a^{2}}{2(b-a)}$.

\section{Triangular distribution}

Symmetrical triangular distribution is supported with the lower limit $\mathrm{a}$, the upper limit $\mathrm{b}$ and the midpoint $\mathrm{m}$, i.e. $\mathrm{a}<\mathrm{m}<\mathrm{b}$ and is represented as $\operatorname{Tr}[\mathrm{a}, \mathrm{m}, \mathrm{b}]$. As $\mathrm{m} \leq \mathrm{T} \leq \mathrm{b}$, we get $\mathrm{T}=\mathrm{b}-\sqrt{(\mathrm{b}-\mathrm{a})(\mathrm{b}-\mathrm{m})(1-\mathrm{k})}$

Thus, the expectation is $H(T)=\int_{a}^{m} x f(x) d x+\int_{m}^{T} x f(x) d x=H_{1}(m)+H_{2}(T)$

where

$\mathrm{H}_{1}(\mathrm{~m})=\int_{\mathrm{a}}^{\mathrm{m}} \frac{2(\mathrm{x}-\mathrm{a})}{(\mathrm{b}-\mathrm{a})(\mathrm{m}-\mathrm{a})} \mathrm{x} \mathrm{dx}=\frac{2}{(\mathrm{~b}-\mathrm{a})(\mathrm{m}-\mathrm{a})}\left[\frac{\left(\mathrm{m}^{3}-\mathrm{a}^{3}\right)}{3}-\frac{\mathrm{a}\left(\mathrm{m}^{2}-\mathrm{a}^{2}\right)}{2}\right] ;$

$H_{2}(T)=\int_{m}^{T} \frac{2(b-x)}{(b-a)(b-m)} x d x=\int_{m}^{T} \frac{2(b-x)}{(b-a)(b-m)} x d x=\frac{2}{(b-a)(b-m)}\left[\frac{b\left(T^{2}-m^{2}\right)}{2}-\frac{\left(T^{3}-m^{3}\right)}{3}\right]$.

\section{Exponential distribution}

For a given exponential distribution for a variable $x$ and mean $\mu$ having $\operatorname{pdf} f(x)=\mu e^{-\mu x}$ for $x \geq 0$; we get $T=$ $\frac{-1}{\mu} \ln (1-\mathrm{k})$ and the expectation is $\mathrm{H}(\mathrm{T})=\int_{0}^{\mathrm{T}} \mathrm{x}\left(\mu \mathrm{e}^{-\mu \mathrm{x}}\right) \mathrm{dx}=\frac{1}{\mu}-\mathrm{e}^{-\mu \mathrm{T}}\left(\mathrm{T}+\frac{1}{\mu}\right)$.

\section{Numerical example}

The models developed are illustrated with a numerical example. The model parameters are obtained from a Mumbai based retail chain consisting of 25 stores specialized in women ethnic fashion apparel. The demand forecast level is considered for a group of Stock Keeping Units (SKUs) that have one type with a combination of different colors and sizes. The US $\$$ is used as a monetary unit for convenience and a conversion rate of Rs. $62 / \$$ is used. The basic parameters of the NVP are: $\mathrm{P}=\$ 60, \mathrm{C}=\$ 30, \mathrm{~V}=\$ 20, \mathrm{~S}=\$ 5$ and $\mathrm{D}_{0}=1000$ units. The demand adjustment provided in Table 2 is determined based on the estimations provided by a group of experts consisting of an apparel designer and three senior managers at the Mumbai office heading the departments of Supply chain, Retailing operations, and Marketing respectively.

Table 2 Judgmental factors considered for the Indian ethnic fashion apparel demand

\begin{tabular}{|l|l|c|}
\hline Factor category & \multicolumn{1}{|c|}{ Event } & Impact \\
\hline Quantum jump factors $\left(\Delta_{1}\right)$ & Improvement in product's design & 200 \\
\hline Trend change factors $\left(\Delta_{2}\right)$ & $\begin{array}{l}\text { Price increase of product to } \\
\text { compensate increased cost of inputs }\end{array}$ & -50 \\
\hline Transient factors $\left(\Delta_{3}\right)$ & $\begin{array}{l}\text { Marketing and advertisement } \\
\text { campaign }\end{array}$ & 100 \\
\hline Transferred impact factors $\left(\Delta_{4}\right)$ & Nil & Nil \\
\hline Total demand adjustment & & +250 \\
\hline
\end{tabular}

According to Table 2, the demand adjustment for contextual information $\Delta$ is equal to $250 . \mathrm{C}_{\mathrm{H}}$ cannot be more than the profit earned per unit and therefore, $\mathrm{C}_{\mathrm{H}}=20$ is used in this example. Assuming the nonlinearity of the total demand adjustment cost and $\gamma>1$, the value of $\gamma$ is assumed to be 1.6. The values of $\alpha, \beta$ and $\eta$ used in this example are $0.95,0.15$ and 0.99 respectively.

The demand is assumed to follow one of the four continuous probability distributions considered; three symmetrical distributions, namely the uniform, the normal and the triangular distribution, and one asymmetrical, the exponential distribution. The four distributions of $\varepsilon$ are specified as: $\mathrm{N}(1,0.01) ; \mathrm{U}(0.7,1.3) ; \operatorname{Tr}(0.7,1,1.3)$; $\operatorname{Exp}(1)$. The mean for all these distributions is 1 and the standard deviation (and range) are selected in order to have an equivalence. Distributions are chosen with considerations of (i) continuous distributions for reasons of mathematical tractability 
and large demand for the product group under consideration (ii) symmetrical nature of the demand distribution as the realised demand can vary equally around the average (iii) different entropy of distributions-entropy is measure of the information carried a demand distribution with higher entropy corresponding to less information (or more uncertainty). The distributions in increasing order of entropy for the given mean and range are normal, triangular and uniform distribution.

The optimal base order quantity $\mathrm{Q}_{0}^{*}$ and the expected profit $E\left(\pi_{0}\right)^{*}$ are computed using (2) and (3) for the stated model parameters and for the four demand distributions. The optimal order quantities are 1076, 1100, 1167 and 1504 for normal, triangular, uniform and exponential distributions respectively. The expected optimal profits are 28660, 28368, 27667 and 14959 for the respective distributions. With $\Delta=250$, the values of $\mathrm{Q}^{*}$ and $\mathrm{E}(\pi)^{*}$ for the unconstrained optimization with different distributions are computed using Theorem 1 and are given in Table 3.

Table 3 Optimal results for the base and the unconstrained optimization cases

\begin{tabular}{|c|c|c|c|c|c|c|}
\hline & Entropy & $\mathrm{Q}_{0}^{*}$ & $\mathrm{E}\left(\pi_{0}\right)^{*}$ & $\mathrm{Q}^{*}$ & $\mathrm{E}(\pi)^{*}$ & $\mathrm{~W}^{*}$ \\
\hline Normal & -0.88 & 1076 & 28660 & 1300 & 30896 & 0.832 \\
\hline Triangular & -0.70 & 1100 & 28368 & 1325 & 30543 & 0.818 \\
\hline Uniform & -0.51 & 1167 & 27667 & 1396 & 29702 & 0.785 \\
\hline Exponential & 1.00 & 1504 & 14959 & 1610 & 15354 & 0.282 \\
\hline
\end{tabular}

It is shown first, that for the positive demand adjustment case, the results show that the revised order quantity and the expected profit are increased compared to the ones of the base case. This means that this model would enhance the economic performance of the retailer. Secondly, the result for exponential distribution, an asymmetrical distribution, is significantly different than those obtained for other three distributions that are symmetrical. Thirdly, the order quantity increases with the entropy of the distribution (with the same mean and range) but the expected profit decreases.

\subsection{Experiments with positive demand adjustment}

The model variables for both the unconstrained and the constrained optimization problems are computed using Theorem 1 and 2 for $\Delta=250$; three values of $\mathrm{C}_{\mathrm{H}}$, viz.; 15, 20, 25; two values of $\gamma$ viz.; 1.6, 1.8 and are presented in Table 4. The resultsshow that the optimal order quantity and the expected profit for both the unconstrained and the constrained optimization are higher than those obtained in the base case; but the imposition of the order size constraint has brought down both order quantity and expected profit. 
Table 4 Experiment results with positive demand adjustment $(\Delta>0)$

\begin{tabular}{|c|c|c|c|c|c|c|c|c|c|c|c|}
\hline \multirow[t]{2}{*}{ Distribution } & \multirow[b]{2}{*}{$\mathrm{C}_{\mathrm{H}}$} & \multirow[b]{2}{*}{$\gamma$} & \multicolumn{4}{|c|}{ Unconstrained Optimization } & \multicolumn{5}{|c|}{ Constrained Optimization } \\
\hline & & & $\mathrm{W}^{*}$ & $D_{N}$ & $\mathrm{Q}^{*}$ & $\pi^{*}$ & $\lambda_{2}^{*}$ & $\mathrm{~W}_{\mathrm{c}}^{*}$ & $\mathrm{D}_{\mathrm{N}}$ & $\mathrm{Q}_{\mathrm{c}}^{*}$ & $\mathrm{E}\left(\pi_{\mathrm{c}}\right)^{*}$ \\
\hline \multirow{6}{*}{$\begin{array}{l}\text { Normal distribution } \\
\qquad \begin{array}{c}\mu=1, \sigma=0.1 \\
Q_{0}^{*}=1076 \\
E\left(\pi_{0}\right)^{*}=28660\end{array}\end{array}$} & \multirow[t]{2}{*}{15} & 1.6 & 1 & 1250 & 1346 & 32075 & 7.2 & 0.806 & 1201 & 1238 & 31586 \\
\hline & & 1.8 & 1 & 1250 & 1346 & 32075 & 6.2 & 0.779 & 1195 & 1238 & 31705 \\
\hline & \multirow[t]{2}{*}{20} & 1.6 & 0.832 & 1208 & 1300 & 30896 & 2.9 & 0.688 & 1172 & 1238 & 30807 \\
\hline & & 1.8 & 0.752 & 1188 & 1279 & 31055 & 2.31 & 0.672 & 1168 & 1238 & 31008 \\
\hline & \multirow[t]{2}{*}{25} & 1.6 & 0.574 & 1143 & 1231 & 30201 & 0 & 0.574 & 1143 & 1231 & 30201 \\
\hline & & 1.8 & 0.569 & 1142 & 1230 & 30472 & 0 & 0.569 & 1142 & 1230 & 30472 \\
\hline \multirow{2}{*}{$\begin{array}{l}\text { Triangular } \\
\text { Distribution }\end{array}$} & \multirow[t]{2}{*}{15} & 1.6 & 1 & 1250 & 1375 & 31709 & 6.25 & 0.842 & 1211 & 1265 & 31268 \\
\hline & & 1.8 & 1 & 1250 & 1375 & 31709 & 5.23 & 0.806 & 1202 & 1265 & 31378 \\
\hline \multirow{4}{*}{$\begin{array}{c}\mathrm{a}=0.7, \mathrm{~m}=1, \mathrm{~b}=1.3 \\
\mathrm{Q}_{0}^{*}=1100 \\
\mathrm{E}\left(\pi_{0}\right)^{*}=28368\end{array}$} & \multirow[t]{2}{*}{20} & 1.6 & 0.818 & 1205 & 1325 & 30543 & 2.4 & 0.696 & 1174 & 1265 & 30462 \\
\hline & & 1.8 & 0.742 & 1186 & 1304 & 30708 & 1.85 & 0.677 & 1169 & 1265 & 30664 \\
\hline & \multirow[t]{2}{*}{25} & 1.6 & 0.564 & 1141 & 1255 & 29867 & 0 & 0.564 & 1141 & 1255 & 29867 \\
\hline & & 1.8 & 0.562 & 1140 & 1254 & 30138 & 0 & 0.562 & 1140 & 1254 & 30138 \\
\hline \multirow{6}{*}{$\begin{array}{l}\text { Uniform distribution } \\
\qquad \begin{array}{c}\mathrm{a}=0.7, \mathrm{~b}=1.3 \\
\mathrm{Q}_{0}^{*}=1167 \\
\mathrm{E}\left(\pi_{0}\right)^{*}=27667\end{array}\end{array}$} & \multirow[t]{2}{*}{15} & 1.6 & 1 & 1250 & 1458 & 30833 & 4.895 & 0.873 & 1218 & 1342 & 30492 \\
\hline & & 1.8 & 1 & 1250 & 1458 & 30833 & 4.025 & 0.822 & 1205 & 1342 & 30587 \\
\hline & \multirow[t]{2}{*}{20} & 1.6 & 0.785 & 1196 & 1396 & 29702 & 1.728 & 0.693 & 1173 & 1342 & 29656 \\
\hline & & 1.8 & 0.720 & 1180 & 1377 & 29879 & 1.318 & 0.670 & 1168 & 1342 & 29856 \\
\hline & \multirow[t]{2}{*}{25} & 1.6 & 0.541 & 1135 & 1324 & 29070 & 0 & 0.541 & 1135 & 1324 & 29070 \\
\hline & & 1.8 & 0.544 & 1136 & 1325 & 29340 & 0 & 0.544 & 1136 & 1325 & 29340 \\
\hline \multirow{4}{*}{$\begin{array}{l}\text { Exponential } \\
\text { distribution }\end{array}$} & \multirow[t]{2}{*}{15} & 1.6 & 0.455 & 1114 & 1675 & 15597 & 0 & 0.455 & 1114 & 1675 & 15597 \\
\hline & & 1.8 & 0.478 & 1120 & 1684 & 15754 & 0 & 0.478 & 1120 & 1684 & 15754 \\
\hline & \multirow[t]{2}{*}{20} & 1.6 & 0.282 & 1070 & 1610 & 15354 & 0 & 0.282 & 1070 & 1610 & 15354 \\
\hline & & 1.8 & 0.334 & 1083 & 1630 & 15514 & 0 & 0.334 & 1083 & 1630 & 15514 \\
\hline \multirow[t]{2}{*}{$\mathrm{E}\left(\pi_{0}\right)^{*}=14056$} & \multirow[t]{2}{*}{25} & 1.6 & 0.194 & 1049 & 1577 & 15231 & 0 & 0.194 & 1049 & 1577 & 15231 \\
\hline & & 1.8 & 0.252 & 1063 & 1599 & 15379 & 0 & 0.252 & 1063 & 1599 & 15379 \\
\hline
\end{tabular}

For example, for the base case with a normal demand distribution, $\mathrm{Q}_{0}^{*}$ and $\mathrm{E}\left(\pi_{0}\right)^{*}$ for the base case are 1076 and $\$ 28660$ respectively, whereas for the unconstrained case, the optimal results show an increase up to $Q^{*}=1300$ and $\mathrm{E}(\pi)^{*}=\$ 30896$, respectively for $\mathrm{C}_{\mathrm{H}}=20$ and $\gamma=1.6$. The order quantity increased by $20.81 \%$ and the expected profit 
increased by $7.8 \%$. In the case of constrained optimization, the constraint reduced the optimal order quantity from 1300 to $\mathrm{Q}_{\mathrm{c}}^{*}=1238(4.8 \%)$ and the expected profit from 30896 to $\mathrm{E}\left(\pi_{\mathrm{c}}\right)^{*}=30807(0.2 \%)$.

Secondly, it can be observed that whenever the optimal order quantity without the constraint $\left(Q^{*}\right)$ exceeds the limit set by the order size constraint, $Q_{\beta}\left[=(1+\beta) Q_{0}^{*}\right]$, the constraint turns binding and the order size is equated to $Q_{\beta}$. Furthermore, the constraint reduced the optimal weight factor, viz. from $0.832\left(\mathrm{~W}^{*}\right)$ to $0.688\left(\mathrm{~W}_{\mathrm{c}}^{*}\right)$.

Thirdly, $\mathrm{C}_{\mathrm{H}}$ adversely affects the optimal order quantity and the expected profit, and the value of these variables is reduced mainly through the reduction caused to the optimal weight factor. The effect of $\gamma$ on these variables is similar.

\subsection{Experiments with negative demand adjustment}

To illustrate the results of the negative demand adjustment, a case when $\Delta=-250$ is provided. Results obtained using Theorems 1 and 2 are presented in Table 5. The results demonstrate that negative demand adjustment reduced both the optimal order quantity and the expected profit.

Table 5 Experimental results with negative demand adjustment $(\Delta<0)$

\begin{tabular}{|c|c|c|c|c|c|c|c|c|c|c|c|}
\hline \multirow[t]{2}{*}{ Distribution } & \multirow[b]{2}{*}{$\mathrm{C}_{\mathrm{H}}$} & \multirow[b]{2}{*}{$\gamma$} & \multicolumn{4}{|c|}{ Unconstrained Optimization } & \multicolumn{5}{|c|}{ Constrained Optimization } \\
\hline & & & $\mathrm{W}^{*}$ & $D_{N}$ & $\mathrm{Q}^{*}$ & $\pi^{*}$ & $\lambda_{1}^{*}$ & $\mathrm{~W}_{\mathrm{c}}^{*}$ & $\mathrm{D}_{\mathrm{N}}$ & $Q_{c}^{*}$ & $E\left(\pi_{c}\right)^{*}$ \\
\hline \multirow{6}{*}{$\begin{array}{l}\text { Normal distribution } \\
\qquad \begin{array}{c}\mu=1, \sigma=0.1 \\
Q_{0}^{*}=1076 \\
E\left(\pi_{0}\right)^{*}=28660\end{array}\end{array}$} & \multirow[t]{2}{*}{15} & 1.6 & 1 & 750 & 807 & 17745 & 9.27 & 1 & 750 & 910 & 17126 \\
\hline & & 1.8 & 1 & 750 & 807 & 17745 & 9.27 & 1 & 750 & 910 & 17126 \\
\hline & \multirow[t]{2}{*}{20} & 1.6 & 0.988 & 759 & 817 & 17010 & 9.27 & 1 & 750 & 910 & 15876 \\
\hline & & 1.8 & 0.855 & 790 & 850 & 18975 & 9.27 & 0.869 & 783 & 950 & 17908 \\
\hline & \multirow[t]{2}{*}{25} & 1.6 & 0.681 & 834 & 897 & 20628 & 9.27 & 0.695 & 826 & 1003 & 19499 \\
\hline & & 1.8 & 0.647 & 841 & 905 & 21332 & 9.27 & 0.657 & 836 & 1014 & 20324 \\
\hline \multirow{6}{*}{$\begin{array}{l}\text { Triangular Distribution } \\
\begin{array}{c}\mathrm{a}=0.7, \mathrm{~m}=1, \mathrm{~b}=1.3 \\
\mathrm{Q}_{0}^{*}=1100 \\
\mathrm{E}\left(\pi_{0}\right)^{*}=28368\end{array}\end{array}$} & \multirow[t]{2}{*}{15} & 1.6 & 1 & 750 & 825 & 17526 & 8.15 & 1 & 750 & 910 & 17168 \\
\hline & & 1.8 & 1 & 750 & 825 & 17526 & 8.15 & 1 & 750 & 910 & 17168 \\
\hline & \multirow[t]{2}{*}{20} & 1.6 & 0.981 & 755 & 830 & 16563 & 8.15 & 1 & 750 & 910 & 15918 \\
\hline & & 1.8 & 0.851 & 787 & 866 & 18597 & 8.15 & 0.867 & 783 & 951 & 17981 \\
\hline & \multirow[t]{2}{*}{25} & 1.6 & 0.676 & 831 & 914 & 20229 & 8.15 & 0.693 & 827 & 1004 & 19577 \\
\hline & & 1.8 & 0.644 & 839 & 923 & 20975 & 8.15 & 0.656 & 836 & 1015 & 20393 \\
\hline \multirow{6}{*}{$\begin{array}{l}\text { Uniform distribution } \\
\qquad \begin{array}{c}\mathrm{a}=0.7, \mathrm{~b}=1.3 \\
\mathrm{Q}_{0}^{*}=1167 \\
\mathrm{E}\left(\pi_{0}\right)^{*}=27667\end{array}\end{array}$} & \multirow[t]{2}{*}{15} & 1.6 & 1 & 750 & 875 & 17000 & 3.6 & 1 & 750 & 910 & 16935 \\
\hline & & 1.8 & 1 & 750 & 875 & 17000 & 3.6 & 1 & 750 & 910 & 16935 \\
\hline & \multirow[t]{2}{*}{20} & 1.6 & 1 & 750 & 875 & 15750 & 3.6 & 1 & 750 & 910 & 15685 \\
\hline & & 1.8 & 0.874 & 781 & 912 & 17693 & 3.6 & 0.877 & 781 & 948 & 17582 \\
\hline & \multirow[t]{2}{*}{25} & 1.6 & 0.701 & 825 & 962 & 19271 & 3.6 & 0.705 & 824 & 1001 & 19154 \\
\hline & & 1.8 & 0.662 & 835 & 974 & 20120 & 3.6 & 0.664 & 834 & 1013 & 20016 \\
\hline \multirow{5}{*}{$\begin{array}{l}\text { Exponential distribution } \\
\qquad \mu=1\end{array}$} & \multirow[t]{2}{*}{15} & 1.6 & 1 & 750 & 1128 & 7469 & 0 & 1 & 750 & 1128 & 7469 \\
\hline & & 1.8 & 1 & 750 & 1128 & 7469 & 0 & 1 & 750 & 1128 & 7469 \\
\hline & \multirow[t]{2}{*}{20} & 1.6 & 1 & 750 & 1128 & 6219 & 0 & 1 & 750 & 1128 & 6219 \\
\hline & & 1.8 & 1 & 750 & 1128 & 6219 & 0 & 1 & 750 & 1128 & 6219 \\
\hline & 25 & 1.6 & 1 & 750 & 1128 & 4969 & 0 & 1 & 750 & 1128 & 4969 \\
\hline
\end{tabular}




\begin{tabular}{|l|l|l|l|l|l|l|l|l|l|}
\hline 1.8 & 1 & 750 & 1128 & 4969 & 0 & 1 & 750 & 1128 & 4969 \\
\hline
\end{tabular}

Secondly, it can be observed that the impact of negative adjustment is at the maximum level, as $\mathrm{W}_{\mathrm{c}}^{*}=1$, and that the service level constraint turns binding. $Q_{c}^{*}$ is obtained by using the equation $Q_{\alpha}\left[=A\left(D_{0}+\Delta\right)\right]$ to the (lower) limit set by the constraint. The limit $\left(Q_{\alpha}\right)$ depends on the demand distribution and on the given parameters. It is equal to 910 , 875,825 for thenormal, the uniform and the triangular distributions respectively.

Thirdly, it is important to note that the constraint reduced the expected profit despite of increase of the order quantity. For example, the constraint reduced the expected profit from 17010 to 15876 for the Normal distribution with $\mathrm{C}_{\mathrm{H}}=20$ and $\gamma=1.6$, where theoptimal order quantity increases from $817\left(\mathrm{Q}^{*}\right)$ to $910\left(\mathrm{Q}_{\mathrm{c}}^{*}\right)$. Fourthly, results show a significant influence of $\mathrm{C}_{\mathrm{H}}$ on the decision variables. The increase in $\mathrm{C}_{\mathrm{H}}$ raises the order quantity by reducing the weight factor when the latter is less than one. But, the same order quantity is maintained with a diminished expected profit if the weight factor is equal to one. Similarly, an increase in $\gamma$ reduces the weight factor if it is less than one and raises the order quantity and the expected profit, but these variables remain unchanged when the optimal weight factor is equal to one.

\subsection{Effect of the order size constraint parameter $(\beta)$}

The effect of $\beta(\beta \geq 0)$ on the model variables for $\Delta=250, \mathrm{C}_{\mathrm{H}}=20$ and $\gamma=1.6$ is discussed here. The constraint gets more liberal as $\beta$ increases and turns redundant at a certain value of $\beta$, considered as the limiting value of the order size constraint parameter $\beta_{1}$. $\beta_{1}$ is equal to 0.208 for the given set of parameters for a Normal demand distribution. Thus, the constraint is binding for $\beta<\beta_{1}$, and the $Q_{c}^{*}$ is equal to the limit set by the constraint, $Q_{\beta}$ [= $\left.(1+\beta) Q_{0}^{*}\right]$. Both $Q_{c}^{*}$ and $E\left(\pi_{c}\right)^{*}$ increase with $\beta$ for $\beta<\beta_{1}$ and converges toward the values obtained in the unconstrained case (viz., $Q^{*}=1300$ and $\mathrm{E}(\pi)^{*}=30896$ ) at $\beta=\beta_{l}$. The constraint is redundant for $\beta \geq \beta_{l}$. The behaviour of $Q_{c}^{*}$ and $E\left(\pi_{c}\right)^{*}$ with respect to $\beta$ is shown in Fig 1 .

The constrained weight factor $\left(\mathrm{W}_{\mathrm{c}}^{*}\right)$ increases linearly with $\beta$ till it converges with unconstrained weight factor $\left(\mathrm{W}^{*}\right)$ at $\beta=\beta_{1}$ viz. $W^{*}=0.831$ at $\beta_{1}=0.208$. Thereafter, weight factor is unaffected by increase in $\beta$. This behaviour is shown in Fig.2.

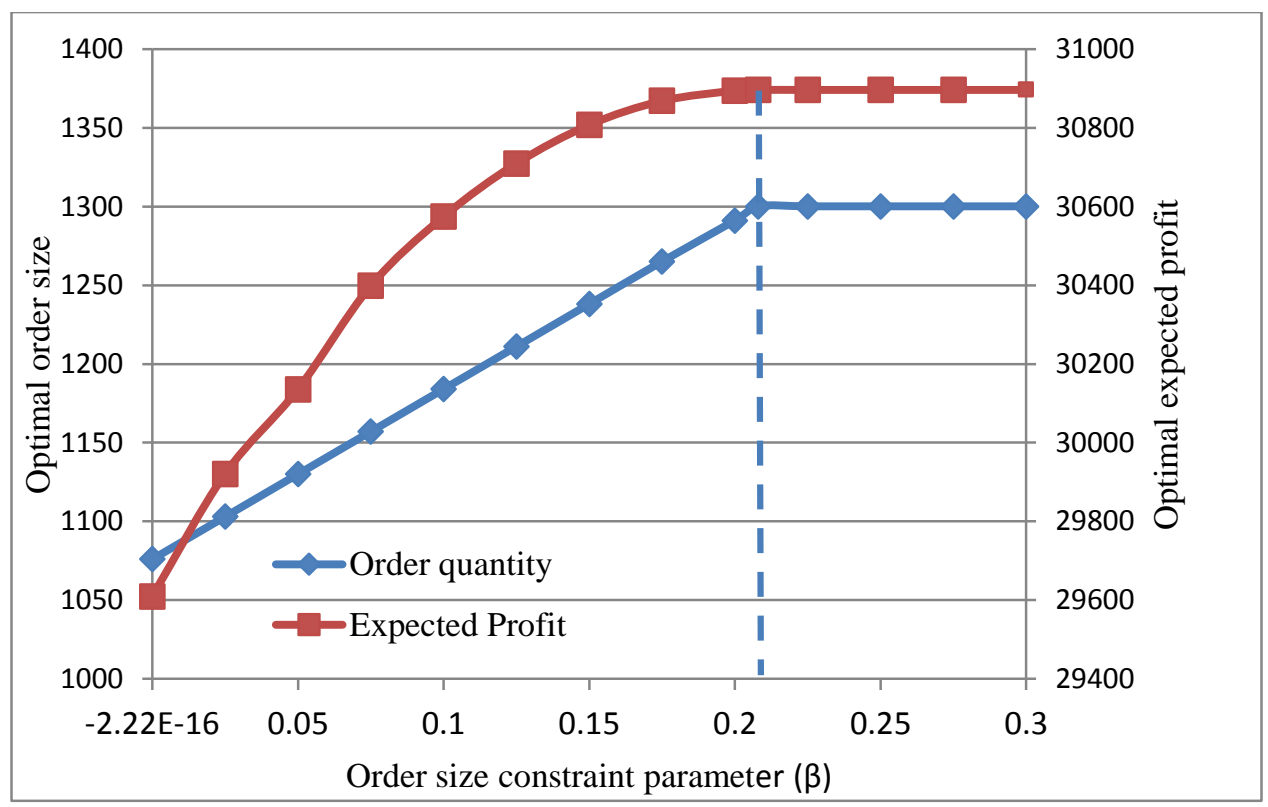

Fig.1.Effect of order size constraint parameter $(\beta)$ on optimal order quantity and optimal expected profit 


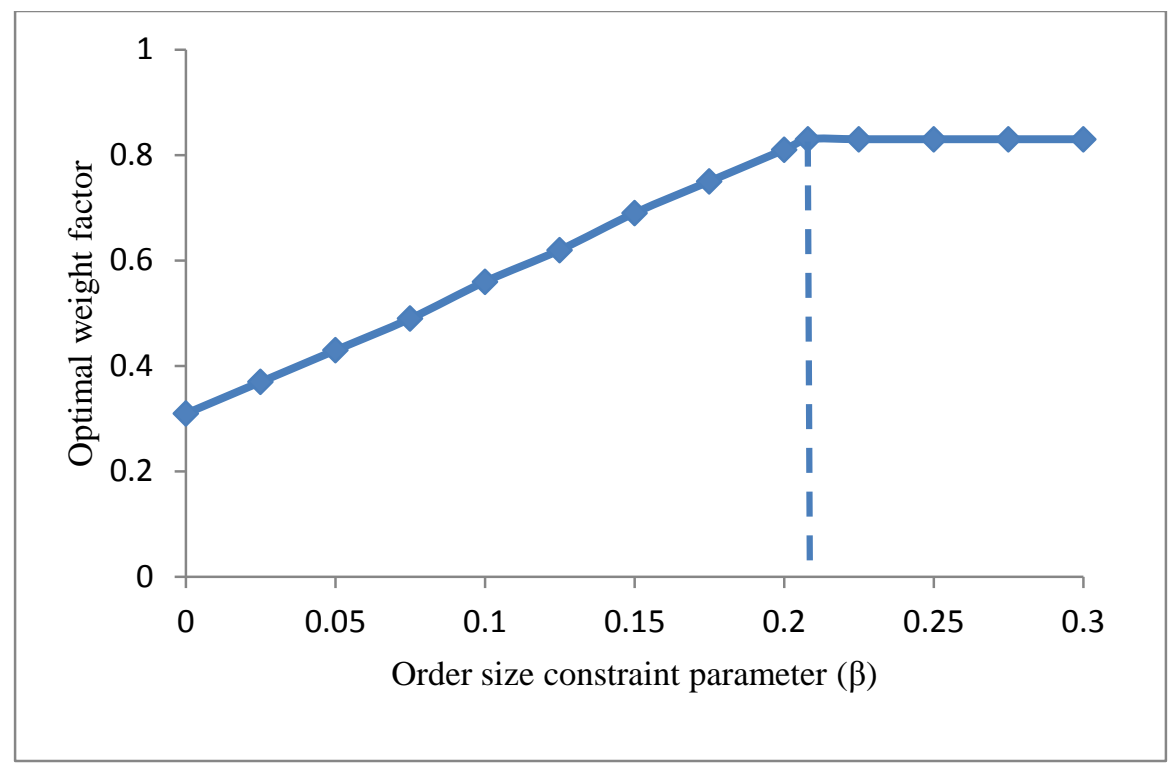

Fig.2.Effect of order size constraint parameter $(\beta)$ on the weight factor

\subsection{Effect of the targeted service level}

The effect of the targeted service level $(\alpha)$ on the model variables for Normal demand distribution and values of $\Delta=$ $250, \mathrm{C}_{\mathrm{H}}=20, \gamma=1.6$ is presented in Table 6 . It can be observed that $\mathrm{Q}_{\mathrm{c}}^{*}$ and $\mathrm{E}\left(\pi_{\mathrm{c}}\right)^{*}$ are affected only above a certain value of $\alpha$, termed as limiting value of target service level $\left(\alpha_{1}\right)$. The value of $\alpha_{1}$ is 0.842 for the given parameters. Thus, the constraint is binding within the interval $\alpha_{l}<\alpha<1$. The expected profit function decreases despite the fact that $Q_{c}^{*}$ increases with respect to $\alpha$ within this interval as presented in Fig. 3 . $W_{c}^{*}$ increases with respect to $\alpha$, but that increase is not significant.

Table 6 Impact of target service level $(\alpha)$ on the optimal weight, order quantity and expected profit

\begin{tabular}{|c|c|c|c|}
\hline$\alpha$ & $\mathrm{W}_{\mathrm{c}}^{*}$ & $\mathrm{Q}_{\mathrm{c}}^{*}$ & $\mathrm{E}\left(\pi_{\mathrm{c}}\right)^{*}$ \\
\hline 0.7 & 0.96 & 817 & 17010 \\
\hline 0.8 & 0.96 & 817 & 17010 \\
\hline 0.842 & 0.96 & 817 & 17010 \\
\hline 0.85 & 0.97 & 824 & 16999 \\
\hline 0.90 & 0.98 & 868 & 16561 \\
\hline 0.95 & 1.00 & 910 & 15876 \\
\hline 0.99 & 1.00 & 949 & 15507 \\
\hline
\end{tabular}




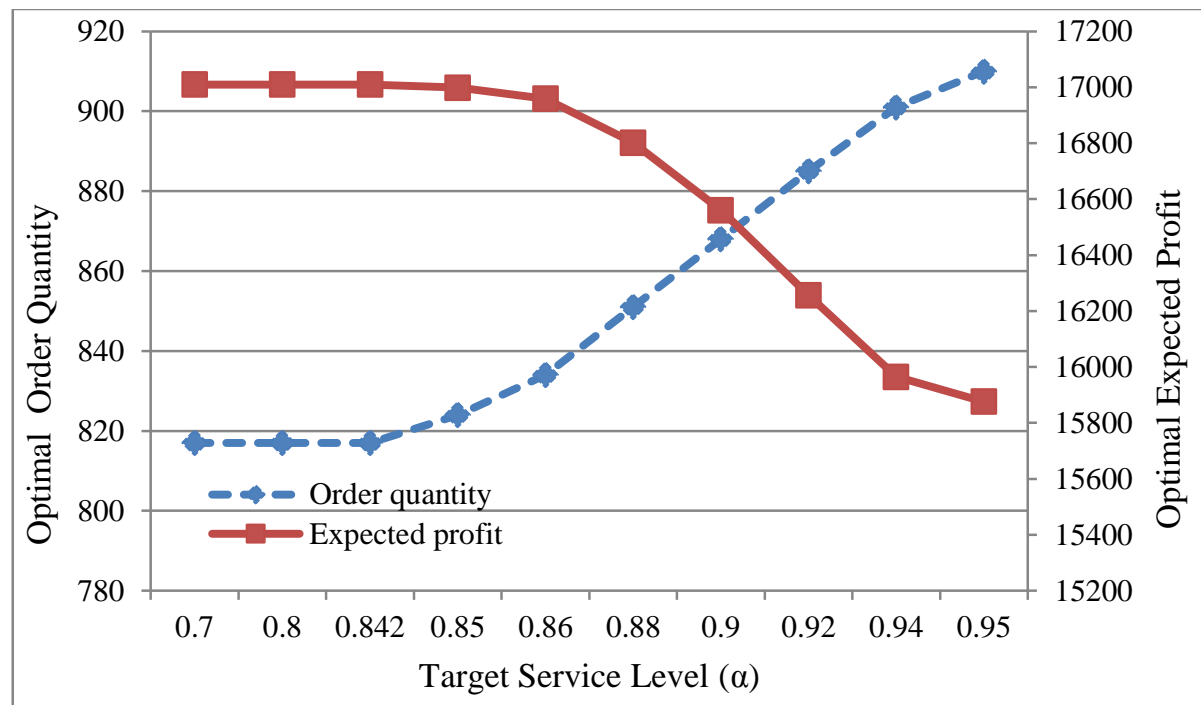

Fig.3. Effect of target service level factor $(\alpha)$ on optimal order quantity and expected profit

\subsection{Effect of the unit demand adjustment cost}

The influence of $\mathrm{C}_{\mathrm{H}}$ on the model variables for the unconstrained optimization with $\Delta=250$ and $\gamma=1.6$ is given in Table 7. Both order quantity and expected profit decrease as $\mathrm{C}_{\mathrm{H}}$ increases, mainly due to the reduction of the value of $\mathrm{W}^{*}$. This behavior is plotted in Fig. 4. The threshold unit demand adjustment cost, determined by Lemma 1 , provides a lower limit value for $\mathrm{C}_{\mathrm{H}}$. For every lower value of $\mathrm{C}_{\mathrm{H}}$ the weight $\mathrm{W}$ is set to 1 . $\mathrm{C}_{\mathrm{HT}}$ is 17.8 for the given parameters. The behavior of $\mathrm{W}^{*}$ with respect to $\mathrm{C}_{\mathrm{H}}$ is shown separately in Fig. 5. Thus, the increase of $\mathrm{C}_{\mathrm{H}}$ in the range $0<\mathrm{C}_{\mathrm{H}} \leq \mathrm{C}_{\mathrm{HT}}$ maintains $\mathrm{W}^{*}=1$ and $\mathrm{Q}^{*}=1346$, but with consequent reduction in the expected profit. However, the increase of $\mathrm{C}_{\mathrm{H}}$ in the range $\mathrm{C}_{\mathrm{H}}>\mathrm{C}_{\mathrm{HT}}$ decreases both $\mathrm{Q}^{*}$ and $\mathrm{E}(\pi)^{*}$, mainly through reduction in $\mathrm{W}^{*}$. At very large (but unpractical) values of $\mathrm{C}_{\mathrm{H}}, \mathrm{W}^{*}$ converges tozero and both $\mathrm{Q}^{*}$ and $\mathrm{E}(\pi)^{*}$ converge to the values seen in the base demand case viz. $Q_{0}^{*}=1076$ and $\mathrm{E}\left(\pi_{0}\right)^{*}=28660$.

Table 7 Impact of unit demand adjustment cost $\left(\mathrm{C}_{\mathrm{H}}\right)$ on the optimal weight, order quantity and expected profit

\begin{tabular}{|c|c|c|c|}
\hline $\mathrm{C}_{\mathrm{H}}$ & $\mathrm{W}^{*}$ & $\mathrm{Q}^{*}$ & $\mathrm{E}(\pi)^{*}$ \\
\hline 5 & 1 & 1346 & 34575 \\
\hline 10 & 1 & 1346 & 33325 \\
\hline 15 & 1 & 1346 & 32075 \\
\hline 17.8 & 1 & 1346 & 31375 \\
\hline 20 & 0.83 & 1300 & 30896 \\
\hline 25 & 0.57 & 1231 & 30201 \\
\hline 30 & 0.42 & 1190 & 29797 \\
\hline 40 & 0.26 & 1147 & 29364 \\
\hline 50 & 0.18 & 1125 & 29145 \\
\hline 60 & 0.13 & 1112 & 29018 \\
\hline 450 & $\approx 0$ & 1076 & 28660 \\
\hline
\end{tabular}




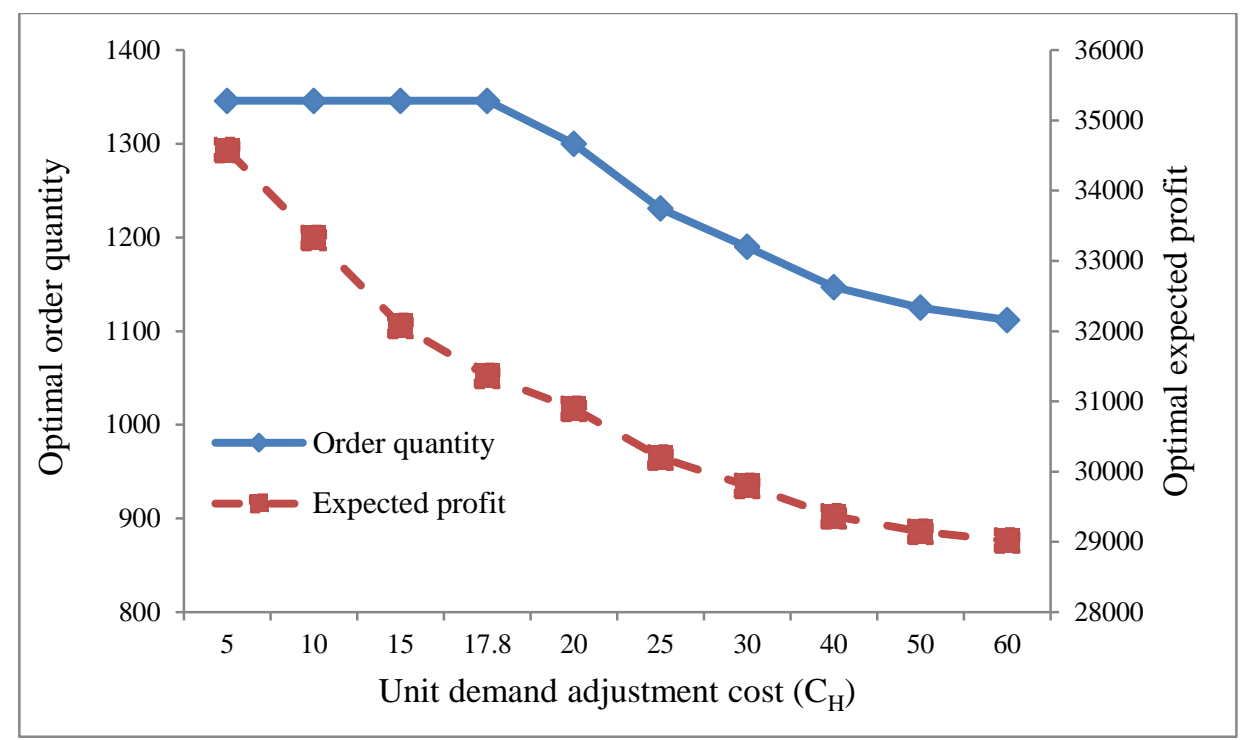

Fig.4. Effect of unit demand adjustment $\operatorname{cost}\left(\mathrm{C}_{\mathrm{H}}\right)$ on order quantity and expected profit

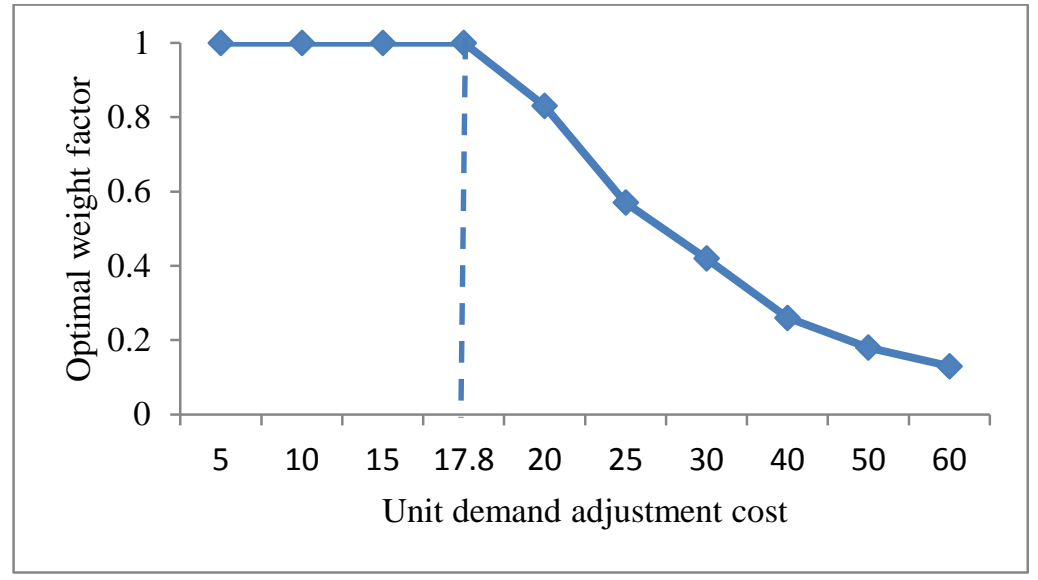

Fig.5. Effect of unit demand adjustment cost on weight factor

\section{Conclusions and managerial implications}

The potential impact of contextual information related to the change of the demand environment and to nonforecastable events obtained between the two stages of the preseason ordering procedure is estimated through expert judgment and is used to revise the demand forecast. Thus, in this paper, inventory models are developed with revised demand forecasts under the NVP setting to determine the optimal order quantity, the weight factor and the expected profit. The models consider bi-directional changes in demand and constraints are imposed for practical considerations. A decision maker may assign a weight $\mathrm{W}(0 \leq \mathrm{W} \leq 1)$ to the demand adjustment suggested by the experts. In that case, the optimization models proposed determine the optimal weight that could be taken as indicative values by decision makers. The unit demand adjustment cost $\left(\mathrm{C}_{\mathrm{H}}\right)$ introduced in the model, can be interpreted as a penalty charged per unit by a supplier for modifying the initial order size, advertising expenditure per unit of accrued demand or an adjustment for the per unit revenue loss in the objective function for offering discount. For practical purposes, $\mathrm{C}_{\mathrm{H}}$ cannot be more than the unit contribution derived by selling the product. 
One of the important novelties of the paper is simultaneous consideration of bidirectional changes in demand through a single model, which otherwise impossible as profit maximization (minimization) model applicable to demand increase (decrease) case always negate the impact of negative (positive) demand adjustment. Secondly, the models determine optimal weight that can be assigned to the demand adjustment suggested through weight factor considering the demand adjustment cost. Thirdly, many a times the objective functions are often overlook the lost sales revenue from unmet demand and consider only shortage penalty cost. The objective function of the models developed includes this loss of lost sales revenue and the solution to such modified objective function provides not only a revised order quantity for both demand adjustment cases, but also provides the same order quantity following either of approaches in the base case.

Fourthly, the results show that retailers would benefit economically if they were to use the models developed. Retailers increase their expected profit through a larger order size in an increasing demand case. On the other hand, in a reducing demand case, retailers still earn an optimal profit by determining an order quantity that minimizes the expected cost. Fifthly, the order quantity and expected profit reduction due to the order size constraint shows expected results. Surprisingly, imposing a service level constraint reduces the expected profit despite raising the order quantity. The loss of expected profit caused by these constraints can be interpreted as a cost a retailer bears for practical considerations of limited space or budget in the former case and for ensuring a defined service level in the latter case. Sixthly, symmetrical demand distributions (normal, uniform, triangular) are found more suitable for these models. Seventhly, entropy is measure of the information carried by a distribution and higher entropy corresponds to less information content (or more uncertainty). For a given mean and range, higher entropy of demand distribution means larger optimal order quantity and lower lesser expected profit. The same has been demonstrated by using different demand distributions having entropy in the increasing order of normal, triangular, uniform and exponential. One of the limitations of the present work is these models are parameter sensitive and conclusions drawn are based on limited numerical experiments. The present work can be extended to the distribution free NVP and multi-constrained optimization.

\section{References}

[1] G. Gallego, I. Moon, The distribution free newsboy problem: review and extensions. J. Oper. Res. Soc. 44(8) (1993) 825-834.

[2] M. Khouja, The single-period (news-vendor) problem: literature review and suggestions for future research. Omega-Int. J. manag. Sci. 27 (1999) 537-553.

[3] Y. Qin, R. Wang, A. J. Vakharia, Y. Chen, M. Serel, The newsvendor problem: Review and directions for future research, Eur. J. Oper. Res. 213(2) (2011) 361-374.

[4] P. Kalpana, A. Kaur, Single-period inventory models with multiple ordering opportunities: a review. Int. J. Log. Syst. Manag. 13(2) (2012) 209-229.

[5] A. Lau, H. Lau, The newsboy problem with price-dependent demand distribution. IIE Trans. 20(2) (1988) 168175.

[6] D. Petrovic, R. Petrovic, M. Vujosevic, Fuzzy models for the newsboy problem, Int. J. Prod. Econ. 45(1-3) (1996) 435-441.

[7] T. L. Urban, R.C. Baker, Optimal ordering and pricing policies in a single-period environment with multivariate demand and markdowns, Eur. J. Oper. Res. 103(3) (1997) 573-583.

[8] H. K. Alfares, H. H. Elmorra, The distribution-free newsboy problem: Extensions to the shortage penalty case, Int. J. Prod. Econ. 93-94 (2005) 465-477.

[9] P. Dutta, D. Chakraborty, Incorporating one-way substitution policy into the newsboy problem with imprecise customer demand, Eur. J. Oper. Res. 200(1) (2010) 99-110.

[10] Y. Yu, J. Zhu, C. Wang, A newsvendor model with fuzzy price-dependent demand, Appl. Math. Modell. 37 (2013) 2644-2661. 
[11] Z. Qin, S. Kar, Single-period inventory problem under uncertain environment, Appl. Math. Comp. 219(18) (2013) 9630-9638.

[12] R. Rossi, S. Prestwich, S.A. Tarim, B. Hnich, Confidence-based optimisation for the newsvendor problem under binomial, Poisson and exponential demand, Eur. J. Oper. Res. 239(3) (2014) 674-684.

[13] M. Lawrence, P. Goodwin, P. O'Connor, D. O"nkal, Judgmental forecasting: a review of progress over the last 25 years, Int. J. Fore. 22(3) (2006) 493-518.

[14] R. Webby, M. O'Connor, Judgmental and statistical time series forecasting: a review of the literature, Int. J. Fore. 12(1) (1996) 91-118.

[15] J. S. Armstrong, F. Collopy, Integration of Statistical Methods and Judgment for Time Series Forecasting: Principles from Empirical Research, in G. Wright and P. Goodwin (eds.), Forecasting with Judgment, John Wiley and Sons Ltd., (1998) 269-293.

[16] P.Goodwin, R.Fildes, Judgmental forecasts of time series affected by special events: Does providing a statistical forecast improve accuracy?, J Behavioral Decision Making,12(1999) 37-53.

[17] R. Fildes, P. Goodwin, M. Lawrence, K. Nikolopoulos, Effective forecasting and judgmental adjustments: an empirical evaluation and strategies for improvement in supply-chain planning, Int. J. Forecasting, 25 (1) (2009) 3-23.

[18] G.J .Lobo, and R.D. Nair, Combining judgmental and statistical forecasts: an application to earnings forecasts, Decision Sciences, 21(1990) 446-60.

[19] R. Batchelor and P. Dua, Forecaster diversity and the benefits of combining forecasts, Man. Sci., 41(1995)6875.

[20] R.Webby,M. O'Connor, and M. Lawrence, Judgmental time series forecasting with domain knowledge, in Armstrong, J.S. (Ed.), Principles of Forecasting: A Handbook for Researchers and Practitioners, Kluwer Academic Publishers, Norwall, MA.

[21] J. Mostard, R. Teunter, R. Koster, Forecasting demand for single-period products: A case study in the apparel industry, Eur. J. Oper. Res. 211(1) (2011) 139-147.

[22] T.M. Choi, D. Li, H. Yan, Optimal two-stage ordering policy with Bayesian information updating. J. Oper. Res. Soc. 54(3) (2003) 846-859.

[23] T. M. Choi, Pre-season stocking and pricing decisions for fashion retailers with multiple information updating, Int. J. Prod. Econ. 106(1) (2007) 146-170.

[24] N.R. Sanders, L.P. Ritzman, Bringing judgment into combination forecasts, J. Oper. Manag. 13(4) (1995) 311321.

[25] F. Marmier, N. Cheikhrouhou, Structuring and integrating human knowledge in demand forecasting: a judgmental adjustment approach. Prod. Plan. Cont. 21(4) (2010) 399- 412.

[26] X. Yan, Y. Wang, A newsvendor model with capital constraint and demand forecast update, Int. J. Prod. Res. 52(17) (2014) 5021-5040.

[27] R.C.Blattberg, and S.J. Hoch, Database models and managerial intuition: $50 \%$ model $+50 \%$ manager. Management Science, 36 (1990) 887-899.

[28] J.R.Trapero, R. Fildes, A. Davydenko (2011), Non-linear identification of judgmental forecasts effects at SKUlevel, J. Fores., 30 (2011) 490-508.

[29] M. Khouja, S. Robbins, Linking advertising and quantity decisions in the single period inventory model, Int. J. Prod. Econ. 86(2) (2003) 93-105.

[30] C.M. Lee, S.L. Hsu, The effects of advertising on the distribution-free newsboy problem, Int. J. Prod. Econ. 129(1) (2011) 217-224.

[31] J. Dai, W. Meng, A risk-averse newsvendor model under marketing-dependency and price-dependency, Int. J. Prod. Econ. 160(2015)220-229.

[32] H. Lau, Simple formulas for the expected costs in the newsboy problem: An educational note, Eur. J. Oper. Res. 100 (1997) 557-561.

[33] C. Kao, W.K. Hsu, A single-period inventory model with fuzzy demand. Comp. Math. Appl. 43(6-7) (2002) 841-848. 
[34] W. Jammernegg, P. Kischka, Risk preferences of a newsvendor with service and loss constraints, Int. J. Prod. Econ. 143 (2013) 410-415.

[35] J. Shi, G. Zhang, J. Sha, Jointly pricing and ordering for a multi-product multi-constraint newsvendor problem with supplier quantity discounts, Appl. Math. Modell. 35 (2011) 3001-3011.

[36] L. Abdel-Malek, M. Otegbeye, Separable programming/duality approach to solving the multi-product Newsboy/ Gardener Problem with linear constraints, Appl. Math. Modell. 37 (2013) 4497-4508.

[37] T. Wang, Q. Hu, Coordination of supply chain with advertise-and-price-setting Newsvendor, Chinese Control and Decision Conference, IEEE (2011) 885-890.

[38] F.S. Hillier, G.J. Lieberman, Introduction to Operations Research, Ninth Edition, McGraw-Hill, New Delhi (2010).

[39] S.D. Wang, Y.W. Zhou, J.P. Wang, Supply chain coordination with two production modes and random demand depending on advertising expenditure and selling price. Int. J. Syst. Sci. 41(10) (2010) 1257-1272.

[40] A. Charnes, and W. Cooper, Chance-constrained programming, Manag. Sci. 6(1) (1959) 73-79.

[41] D. Panda, S. Kar, K. Maity, M. Maiti, A single period inventory model with imperfect production and stochastic demand under chance and imprecise constraints, Eur. J. Oper. Res. 188(1) (2008) 121-139.

[42] L. Nagar, P. Dutta, K. Jain, An integrated supply chain model for new products with imprecise production and supply under scenario dependent fuzzy random demand, Int. J. Syst. Sci. 45(5) (2014) 873-887.

[43] L. Abdel-Malek, and R. Montanari, An analysis of the multi-product newsboy problem with a budget constraint, Int. J. Prod. Econ. 97(3) (2005) 296-307. 